\title{
LAS CLAVES DEL ÉXITO EDUCATIVO: EL CASO FINLANDÉS*
}

\author{
Inger Enkvist
}

\begin{abstract}
Resumen: El presente informe analiza el sistema educacional de Finlandia y los factores determinantes que han contribuido a su exitoso desempeño en las evaluaciones PISA. Se concluye que el secreto del éxito del sistema educativo de Finlandia radica, principalmente, en el excelente nivel de sus profesores y, en segundo lugar, en las prácticas pedagógicas "tradicionales", en contraposición con las nuevas tendencias pedagógicas. Es más, se argumenta que la "nueva pedagogía" sería la gran responsable del empeoramiento de la educación en Suecia y en gran parte de los países desarrollados. La falta de disciplina en los alumnos y de liderazgo en los profesores, la preponderancia del método por sobre el contenido, la no ejercitación de la memoria, el no incentivo de los hábitos de lectura, la falta de exigencia, de evaluaciones y tareas, etc., serían las causas del deterioro no sólo de la calidad académica, sino también de la conducta de los estudiantes. Por último, se sostiene que los criterios de evaluación de los
\end{abstract}

INGER ENKVIST. Doctora en Letras por la Universidad de Goteborg, especializada en el estudio comparativo de los sistemas de educación. Catedrática de español en la Universidad de Lund, Suecia, y asesora del Ministerio de Educación sueco.

* Informe de investigación. 
informes de la OCDE y de las políticas públicas suecas de educación adolecen de un sesgo economicista, donde prima la relación entre inversión y educación, por una parte, y el empleo y los salarios, por otra, dejando de lado los temas propiamente educacionales.

Palabras clave: educación, Finlandia, Suecia, prácticas pedagógicas, "nueva pedagogía".

Recibido: septiembre 2010; aceptado: octubre 2010.

\section{THE KEYS TO EDUCATIONAL SUCCESS: THE CASE OF FINLAND \\ Inger Enkvist}

Abstract: This report analyzes the system of education in Finland and the determining factors that have contributed to its successful performance in PISA evaluations. It concludes that the secret to the success of the Finish education system lies mainly in the excellent level of its teachers, and secondly, in the "traditional" pedagogical practices in opposition to the new pedagogical trends. The "new pedagogy" - it is argued - is mostly responsible for the worsening of education in Sweden and in a large part of developed countries. The lack of discipline among students and of leadership by teachers, the preponderance of method over content, failure to exercise memory, no incentives that encourage reading habits, the lack of exigency, of evaluations and homework, etc., are behind the deterioration not only of academic quality, but also in the conduct of students. Lastly, it is pointed out that the standards for evaluation in the reports by the OECD and the Swedish public policies contain an economic bias where the relationship between investment and education, on the one hand, and between employment and salaries, on the other hand, prevail, leaving aside educational matters.

Keywords: education system, Finland, Sweden, pedagogical trends, "new pedagogy".

Received: September 2010; accepted: October 2010. 
¿ 2 ué es lo que da buen resultado en la educación? Finlandia es la campeona mundial de educación según los informes PISA y ofrece, por eso, un material excepcional para reflexionar sobre la organización de la educación, las inversiones, la formación docente, la autonomía de los centros y la cantidad de opciones ofrecidas a los alumnos. Para que se pueda entender bien el logro finlandés se van a mencionar también otros informes internacionales de actualidad, se van a introducir comparaciones con los demás países escandinavos y se darán algunos datos de la historia de Finlandia como trasfondo.

Desde el final de la segunda guerra mundial, casi todos los países del mundo han invertido en la educación de sus jóvenes ciudadanos. Han prolongado la educación obligatoria, en general hasta los 16 años, para obtener a la vez más igualdad entre los ciudadanos y una mano de obra más calificada. Sin embargo, ha habido dudas a propósito de qué hacer con algunos "nuevos" alumnos que no demuestran un interés espontáneo por el estudio. Una medida frecuente ha sido cambiar la formación docente para que los futuros docentes organicen la actividad tomando en cuenta la voluntad y el interés del alumno, es decir, el método elegido ha sido insistir en la obligación del docente de crear un interés en el alumno por el aprendizaje más que en exigir un esfuerzo por parte del alumno. En particular, en los países de bienestar material, los adultos no han querido, o no han osado, exigirles esfuerzos a sus jóvenes, a pesar de que estudiar siempre ha significado esfuerzo.

Esta nueva pedagogía, dominante en los países occidentales, se ha impuesto a través de los departamentos de pedagogía y de la formación docente. Cuando han empezado a bajar los resultados y han aparecido cada vez más casos de conducta irrespetuosa dentro de los establecimientos educativos, la respuesta de los pedagogos y de las autoridades ha sido afirmar que la sociedad ha cambiado y por eso, por simple reflejo, también la escuela. Las consecuencias de esta actitud han sido dramáticas $\mathrm{y}$, entre otras cosas, los mejores profesores tienden a dejar la escuela para buscarse otras salidas profesionales. En esa discusión, cualquiera que diga que antes las cosas eran mejores se ve automáticamente calificado de retrógrado, porque los nuevos pedagogos afirman que la orientación es correcta, pero que la culpa la tienen los cambios ocurridos en la sociedad. 
En esta situación aparecieron las comparaciones internacionales que atraen cada vez más interés. Entre ellas, las más famosas son los informes PISA, elaborados por la OCDE, que ofrecen una profusión de datos sobre los alumnos y sobre los sistemas educativos. Suelen salir en los primeros puestos países asiáticos como Corea del Sur y Japón; los países angloparlantes y Estonia y los Países Bajos; pero por ahora la estrella es Finlandia. ¿Cómo entender que algunos de los países europeos de excelente tradición educativa ya no son tan buenos y por qué es Finlandia una excepción?

\section{Los profesores son la clave}

Muchas veces, la primera reacción de los políticos ante unos resultados decepcionantes en las comparaciones de PISA ha sido intentar aumentar las inversiones. Sin embargo, no hay una relación directa entre la inversión en educación y el resultado, lo demuestra un informe publicado por la consultoría McKinsey. Se trata de un estudio de benchmarking que identifica los factores clave en los países con buenos resultados educativos y los países que están mejorando sus resultados de manera rápida.

El informe McKinsey muestra que el factor clave en educación son los profesores ${ }^{1}$. Lo importante no es tanto la inversión en edificios ni materiales sino en la inteligencia y la preparación del profesor. ¿Qué hacen los países más exitosos? 1. Eligen a sus futuros profesores entre los mejores alumnos que salen de la enseñanza media. 2. Para poder hacerlo, les pagan tanto como se paga a otros profesionales de alto nivel. 3. Los educan con los mejores profesores universitarios. 4. Les garantizan un puesto de trabajo después de la formación. 5. Les dan un seguimiento durante los primeros años de ejercicio de la profesión. Finlandia hace más o menos esto y, además, ha organizado un servicio eficaz de apoyo para ayudar a los alumnos retrasados en alguna materia.

El informe McKinsey también demuestra que son menos exitosas medidas como 1) invertir más dinero en la educación de manera general, 2) dar más autonomía a los centros escolares sin cambiar otra cosa,

${ }^{1}$ Michael Barber y Mona Mourshed, How the World's Best-performing School Systems Come Out on Top. McKinsey, 2007 (www.mckinsey.com/locations/ukireland/index.aspx). 
3) disminuir el número de alumnos por grupo, o 4) aumentar los salarios de los profesores sin cambiar nada más. La novedad del informe es que subraya que hay que ocuparse en primer lugar de lo esencial y que lo esencial es la calidad del profesor. Como dice uno de los entrevistados en el informe: un profesor no puede dar lo que no tiene.

Disminuir el número de estudiantes por grupo es actualmente la medida más reclamada por los sindicatos docentes. Sin embargo, el informe señala que esta medida es muy cara y menos eficaz que otras. Hasta podría tener un efecto perverso, porque si hay menos alumnos por grupo, se necesita más profesores $\mathrm{y}$, si se necesita más profesores, no es posible mantener una exigencia muy alta, porque simplemente no hay suficientes personas de excelente calidad que quieran ser profesores. Además, si hay que reclutar a muchos más profesores y la masa salarial es la misma, el salario de cada uno no va a ser muy alto, y esto va a disuadir de la carrera docente a los estudiantes brillantes. Al revés, lo que hay que hacer es atraer a las personas más capaces, ofrecerles un buen salario y mostrarles mucho aprecio de modo que quieran quedarse en la profesión y que muchos alumnos puedan gozar del privilegio de aprender con ellos. Sin embargo, si un país quiere aplicar los resultados de estas experiencias, es probable que tenga que introducir algunos cambios:

- Si se acepta que lo más importante para el alumno es tener un buen profesor, los sindicatos se verán frente a un gran reto. Van a tener que anteponer el bien de los alumnos y del país a su propia tradición colectivista. Es probable que tenga que cambiar la legislación laboral.

- Para atraer a buenos candidatos habrá que cambiar la formación docente, lo cual quiere decir librar una batalla con los departamentos de pedagogía para quitar lo que no es realmente útil.

\section{La nueva pedagogía}

¿En qué consiste esta pedagogía que ha resultado criticada en los informes McKinsey? En dos palabras, consiste en la idea de que sería posible dar una educación a alguien sin que el receptor tuviera que esforzarse. Esta idea se combina con otra que pretende que el contenido de la educación no es lo que importa, sino aprender una serie de métodos. Estas ideas han seducido a padres y a gobiernos en muchos países occidentales. Otra manera de explicar esta nueva pedagogía es 
describirla a través del ejemplo sueco, un país pionero en la aplicación de esa novedad ${ }^{2}$. Como ejemplo, Suecia tiene la ventaja de ser un caso bastante puro en el sentido de que el país tenía un buen nivel económico y educativo, y había gozado de muchos años de paz social, cuando los políticos decidieron utilizar la educación para que el país fuese más igualitario todavía. A finales de los 60 , se introduce la escuela comprensiva obligatoria hasta la edad de los 16 años; a la vez, la convivencia pasa a ser la meta principal y no el aprendizaje. El nuevo ideario está compuesto de varios factores:

- La psicología suele debatir qué parte de nosotros se define por la genética y qué parte por el ambiente. Los reformadores están resueltamente del lado del ambiente y, según su teoría, que se podría llamar la "teoría del entorno", la convivencia con los alumnos con más facilidad de aprendizaje debe servir como entorno favorable para el desarrollo de los alumnos con más desventajas. Que todos los alumnos logren el máximo de conocimientos ya no es lo más importante sino que el resultado sea tan similar como posible. Debe desaparecer lo que diferenciaba a un alumno de otro. Todos deben estudiar las mismas materias a la vez que se quitan, en gran medida, los exámenes, las tareas para la casa y las notas. Todos deben estudiar al mismo ritmo y el resultado debe ser más o menos igual.

- La igualdad debe obtenerse mediante la organización del aula. La idea incluye incorporar también a alumnos con serios problemas de conducta y de aprendizaje, con lo cual se perturba la necesaria tranquilidad para poder estudiar.

- Hay que centrarse más en el método de estudio que en el contenido. Supuestamente, aprender métodos resulta un atajo para los alumnos. En vez de llenar el cerebro con detalles innecesarios, los alumnos van a hacerse con instrumentos para poder resolver cualquier duda en el futuro. Centrarse en los métodos y no en los contenidos se considera una modernización y una manera más eficaz de usar el tiempo de los alumnos y el dinero del Estado. Esta idea tiene consecuencias para la formación docente, porque significa que ya no es tan importante estudiar las materias como la manera de enseñar, la didáctica.

${ }^{2}$ Véase también Inger Enkvist, La Educación en Peligro [2000] 2010, y Repensar la Educación [2006] 2010. 
- Una nueva teoría psicológica y filosófica está en el origen de estos cambios, el "constructivismo", una teoría que afirma que el conocimiento del ser humano consiste en una construcción de ideas y estructuras en el cerebro. Todo lo que sabemos está guardado en el cerebro. Sin embargo, los pedagogos constructivistas suelen ir más lejos, porque muchos de ellos niegan la existencia de una realidad independiente de la percepción y la voluntad humana. Creen que todo conocimiento es un invento, una creación, sin una relación objetiva con una realidad objetiva. Aprender se redefine como que el alumno debe estar activo y libre, construyendo sus propios conocimientos. En vez de un énfasis en el aprendizaje de ciertos conocimientos, el centro de la nueva pedagogía pasa a ser la creatividad y la expresión de la propia personalidad del alumno.

- Es difícil organizar un aula en la que se juntan alumnos muy diferentes y en la que cada uno debe crear su propio conocimiento y expresarse. La nueva tarea del profesor es inventar tareas que puedan atraer y ocupar a los alumnos. Resulta contradictorio tener un marco curricular con contenidos si al mismo tiempo se invita a los alumnos a elegir lo que quieran estudiar. Esto explica que los currículos hablen cada vez más de métodos y de valores que de contenidos.

- Aumenta, además, el énfasis en el derecho del alumno a ser diferente y el respeto que le debe la escuela. Ya no se habla del deber del alumno de estudiar y de comportarse bien, sino de la obligación de la escuela de adecuarse a la voluntad y las necesidades especiales del alumno, aunque éste no se haya esforzado por estudiar.

Este sistema de educación ha seducido en primer lugar a los pedagogos de los países con muchos recursos y con habitantes acostumbrados a hacer lo que les gusta. Lo grave es que la nueva pedagogía describe una antiescuela. Las escuelas fueron creadas una vez con el objetivo de que los alumnos aprendieran lo que la sociedad había decidido que era útil aprender, pero ¿cuál es el propósito de la escuela si el alumno decide lo que quiere hacer? ¿Llegaremos a tener tantas aulas como alumnos? El derecho a la diferencia socava por completo la idea de la escuela y el papel del profesor, imposibilitado de saber todo lo que cada alumno pueda decidir estudiar. Éste es uno de los principales motivos del malestar existente entre el profesorado. En la pedagogía tradicional, el profesor presenta y explica un contenido al alumno, pero el constructivismo convierte al profesor en mero "facilitador". El alumno 
se convierte en el "centro del proceso pedagógico" y, en vez de aprender una materia, "aprende a aprender". El profesor debe encontrar maneras atractivas, lúdicas, de aprendizaje, despertando la motivación del alumno, pero después, supuestamente, el alumno aprende por sí solo. Por eso, se oye hablar de "buscar información" en vez de "aprender". Y además, ¿cómo se conjuga esto con el ideal del igualitarismo? ¿No serán necesariamente diferentes los resultados de los diferentes alumnos si se procede así? Sí, serán diferentes pero el problema se resuelve adjudicando a todos los resultados un valor similar. Se deduce de lo anterior que está latente en la nueva pedagogía un desprecio hacia la cultura. Si se considera que cualquier alumno puede elegir libremente qué rescatar de la cultura, ésta no se tiene en gran estima. Además, por lo visto, todos los alumnos son capaces de desarrollar todo tipo de saber que a los genios humanos de diferentes áreas les ha llevado siglos desarrollar.

La pedagogía que se acaba de describir no tiene ningún nombre oficial. Ya que es hegemónica, en los departamentos de pedagogía de los países occidentales es simplemente "la" pedagogía actual. Para referirse a ella, se utilizará en lo siguiente el nombre de "la nueva pedagogía".

\section{Dinero y pedagogía}

Suecia es uno de los países pioneros de una nueva pedagogía más lúdica y libre, pero ahora empiezan a menudear los informes que señalan los peligros de esta pedagogía. Un informe de Fölster et al. particularmente contundente se publicó en 2009, centrándose en la relación entre educación y dinero ${ }^{3}$. El informe merece nuestra atención porque salen hechas polvo unas cuantas afirmaciones comúnmente aceptadas como verdades. Los autores son economistas y describen la escuela como una organización con una meta (producir conocimiento) y con ciertos recursos (en primer lugar, los profesores). Empiezan diciendo que si una empresa hiciera lo que hace la escuela pública, no sólo quebraría, sino que antes tendría que soportar la ira de los accionistas por la falta de transparencia económica. Los tres autores han estudiado la escuela obligatoria sueca - que matricula a los alumnos entre los 7 y los 16 años de edad - con la ayuda de las estadísticas oficiales, basándose en primer lugar en cifras correspondientes al período 1999-2009. En lo

\footnotetext{
${ }^{3}$ Stefan Fölster et al., Den orättvisa skolan, 2009.
} 
siguiente, las tesis principales del informe se presentarán como "verdades desmontadas" para dar énfasis al interés que representan los datos.

Bajan los resultados aunque no se han recortado los recursos. Los recursos de la escuela sueca han aumentado en un 8 por ciento desde el 1993. Sin embargo, al mismo tiempo, el número de alumnos, que después de los años obligatorios no tienen aprobadas las materias centrales, ha aumentado en un 30 por ciento en los últimos diez años. Ha aumentado también el número de alumnos que suspenden más de una materia, y ha aumentado el número de municipios con más de un 25 por ciento de alumnos suspendidos, lo cual corresponde a una duplicación del número de municipios en esa situación. ¿Cómo es posible que no todos los ciudadanos pongan el grito en el cielo?, se preguntan los autores.

No hay una clara relación positiva entre la inversión del municipio y los resultados de los alumnos. En la Dirección General de las Escuelas se calcula un índice llamado SALSA sobre el resultado "previsible" de un colegio en cierta área según el nivel de educación de los padres, el nivel de desempleo y otros indicadores socioeconómicos. Ni siquiera tomando en cuenta este índice se puede mostrar una clara relación entre la inversión del municipio y los resultados.

Lo importante no es el nivel socioeconómico de la familia. La prueba más contundente de esta afirmación es la comparación entre los resultados de los chicos y las chicas. Ya que proceden de las mismas familias, deberían tener los mismos resultados y eso está lejos de ser así. Las chicas aventajan a los chicos en todo, y eso es particularmente notable entre los alumnos inmigrantes.

Lo decisivo para la calidad de la enseñanza no es la presencia en el aula de alumnos inmigrantes. Hay inmigrantes tanto en los colegios que han mejorado su rendimiento como en los colegios que han bajado, y hay grupos sin inmigrantes tanto entre los que han mejorado su rendimiento como entre los que han bajado.

Lo importante no son las características socioeconómicas o la situación geográfica del municipio, sino el "ethos escolar" que también se podría llamar el "ambiente escolar". Los colegios exitosos se encuentran en todo tipo de municipio: pequeño, grande, rural y urbano. En un mismo municipio puede variar la calidad de los colegios públicos, como también puede variar la calidad de los concertados.

Crea un vacio fomentar la autonomía administrativa municipal sin una legislación adecuada y sin evaluaciones. La combinación de 
una fuerte ideología educativa igualitaria con la ausencia de posibilidades de tomar medidas para asegurar la paz y la tranquilidad en las aulas ha llevado a que nadie se atreva a tomar decisiones. Los autores señalan una ausencia de liderazgo en tres niveles: en la Dirección General de las Escuelas, entre los directores de los colegios y entre los profesores en el aula.

Una y otra vez, los autores se asombran ante la manera de funcionar de la Dirección General de las Escuelas. Unos ejemplos: de sus 136 publicaciones de los últimos años, sólo unas cuantas mencionan el tema de cómo mejorar la enseñanza. Se recogen informaciones y estadísticas de todo tipo y hay inspecciones, pero no se toman medidas basadas en la información recogida. Los profesores en ejercicio que acuden a los cursos organizados por la Dirección General de las Escuelas cuentan que los responsables les "devuelven la pelota", preguntándoles a los profesores qué sugieren ellos. Los autores confiesan su asombro ante tanta resistencia a transmitir conocimiento en un sistema social organizado para transmitir conocimiento.

La falta de liderazgo también se nota entre los directores de los colegios que no toman medidas para controlar o encarrilar a los empleados. En primer lugar, los autores señalan que el grupo clave de los profesores constituye sólo un 63 por ciento de la plantilla y que hay una veintena de otros grupos presentes en la escuela como, por ejemplo, asistentes sociales, monitores del tiempo libre, enfermeras, oficinistas y consultores pedagógicos. Desde 1999, estos otros grupos han aumentado en un 21 por ciento, mientras que los profesores han aumentado en un 10 por ciento. Cuando baja el número de alumnos en un barrio, se despide a los profesores, pero no a los empleados de las otras categorías. Los autores señalan que estas cifras constituyen una ilustración de que la escuela está dejando cada vez más su tarea principal de enseñar. Además, los autores han consultado una investigación sobre cómo se utiliza el tiempo de los profesores. En promedio, los docentes están en el aula con los alumnos un 30 por ciento de su tiempo y utilizan otro 10 por ciento para las tutorías individuales. El resto del tiempo se aprovecha para la preparación de las clases, las reuniones y "otras cosas". Los autores no salen de su asombro. ¿Qué empresa podría prosperar si los empleados se dedicaran a "otras cosas"? La falta de liderazgo del profesor en el aula es otro problema. Los autores se refieren a la investigación llamada "escuelas exitosas", que subraya la importancia de que los adultos dirijan la actividad. 
No es el número de profesores lo que importa, sino la calidad. El problema no es el número de alumnos por profesor. Durante el período estudiado, en promedio ha habido 12 alumnos por profesor. No hay mejor resultado en los municipios que tienen una ratio menos alta. Al revés, algunos de los colegios más exitosos tienen menos profesores, pero utilizan mejor el tiempo de estos profesores. Entre estos colegios hay bastantes colegios concertados.

En resumen, este informe dice lo mismo que el informe McKinsey: el factor más importante para la calidad de la enseñanza es la calidad del profesor. Durante varias décadas ha bajado el interés de los buenos estudiantes por entrar en la formación docente. Las razones son varias pero una es que, en la actual formación docente en Suecia, se pone mucho énfasis en la teoría pedagógica y menos en las materias que el futuro docente va a enseñar. Otra razón importante es que, entre 1993 y 2007 , los salarios de los docentes han aumentado en un 17 por ciento, mientras que los de los ingenieros han subido en un 32 por ciento y los de los médicos en un 52 por ciento.

Ante la falta de vocación para la formación docente, varias universidades han admitido a estudiantes con niveles más bajos de conocimientos. Después, la formación docente no ha sabido elevar suficientemente el nivel de estos estudiantes, y son particularmente graves los casos de los futuros docentes de primaria y los de matemáticas de la secundaria. El nivel de algunos futuros docentes es tan bajo que necesitan clases de apoyo para obtener el aprobado en su propia formación. Si ahora están bajando los conocimientos de los alumnos de la escuela obligatoria en matemáticas, en ciencias naturales y en comprensión lectora, ¿no tendrá relación con el nivel más bajo de los docentes?

La competencia de las escuelas concertadas es beneficiosa. La calidad de la escuela pública en un área mejora si se establece allí una concertada. Según un informe reciente de la Dirección General de las Escuelas no es correcta la acusación de que las concertadas suban el nivel de las notas para atraer a más alumnos. Según los autores, las concertadas obtienen un mejor resultado, en gran parte, porque utilizan mejor los recursos y, sobre todo, el tiempo de los profesores. En Suecia, la posibilidad de crear colegios concertados surgió a comienzos de los años 90 y ahora hay en la escuela obligatoria un 12 por ciento de colegios concertados. A pesar de ser relativamente pocos, hay 24 colegios concertados entre los 50 mejores colegios de Suecia y entre los 20 me- 
jores hay 11 colegios concertados, todo esto después de tomar en cuenta el índice sueco SALSA que calcula el resultado educativo que se espera en un área basándose en el nivel socioeconómico.

El tiempo de los alumnos debe usarse para el aprendizaje y no para otras actividades. Se han introducido en las escuelas muchas actividades loables en sí, pero que quitan tiempo al aprendizaje. Además, el "buenismo" daña seriamente la calidad de la educación porque los propios alumnos contribuyen a disminuir la eficacia de la enseñanza por su falta de respeto por el sistema escolar. Muchos llegan tarde, están "enfermos", piden "libre" para diferentes actividades de ocio, además de estar ausentes sin ninguna justificación. Como contraste, los autores dan ejemplos de escuelas exitosas en barrios difíciles de otros países que casi no tienen absentismo sino que, al revés, exigen que los alumnos hagan sus tareas en casa, que acudan cuando se dan clases de apoyo y también cuando se ofrece enseñanza obligatoria durante las vacaciones.

Los autores mencionan que, para Suecia, lo sucedido en el mundo de la educación es un cuento de horror. Los informes TIMMS constatan que, en matemáticas, Suecia tenía el puesto número 5 en 1995 y en 2007 había bajado al puesto número 12; en puntaje había bajado de 540 a 491. En ciencias naturales, Suecia estaba en 1995 en el puesto número 4 y en 2007 en el número 12, lo cual en puntos corresponde a un descenso de 553 a 511. Tal como andan las cosas, en la próxima medición es probable que Suecia siga bajando. En la recogida de datos de 2007, ningún país de los 18 que participan en TIMMS había perdido tanto.

¿Cómo ha sido posible que suceda todo esto? Los autores son economistas y obviamente han tomado la decisión de no decir nada de la pedagogía recomendada a los docentes. Por eso, la ideología pedagógica que está en el origen de esta transformación negativa viene a ser un "dato escondido" no explicado. Los autores utilizan un tono inocente, partiendo de la suposición de que, para todo el mundo, la meta principal de la educación es que los alumnos tengan éxito. Las recomendaciones de los autores son varias:

- Las metas deben ser posibles de medir. Si se miden los resultados, es automático que la escuela deje de lado las tareas no centrales a su misión.

- Los profesores deben estar más en el aula y todas las actividades que no tienen que ver directamente con el aprendizaje deben disminuir. 
Los autores recomiendan que las escuelas se agrupen en redes para usar en común un material ya elaborado, con lo cual disminuiría el tiempo requerido por los docentes para la preparación de material. Los autores han visto cómo algunas escuelas concertadas logran un buen resultado de este modo. Además, los profesores podrían desempeñarse de manera más flexible, algunas veces en grupos muy grandes para explicar algo a muchos alumnos y otras veces en grupos pequeños para escuchar las presentaciones orales de los alumnos.

- Una sugerencia que no gustará a todos es la recomendación de considerar el trabajo docente como cualquier actividad profesional exigiendo una presencia de cuarenta horas semanales en el centro con el mismo número de semanas de vacaciones que los demás empleados.

- Otra recomendación es instaurar un programa de salario flexible y abrir la posibilidad de avanzar en la profesión. Se debe combinar la evaluación de los profesores con una formación continua a cargo de los mejores colegas del centro. Es importante combinar el éxito del profesor con el éxito global del colegio para que se fomente un ethos del colegio más que una competición individual.

- Una última sugerencia es abrir la posibilidad de una "formación docente concertada".

\section{Los informes PISA}

Es famoso que los informes PISA de la OCDE incluyan una comparación entre países, resumida en un ranking, comparación de la cual actualmente es campeona Finlandia. La comparación se hace entre alumnos de quince años en comprensión lectora, matemáticas y ciencias naturales. Hubo recolección de datos en 2000, 2003 y 2006, y está en marcha la que corresponde al futuro informe 2009. Los datos son cada vez más valiosos, pues ahora permiten ver no sólo cómo se posiciona un país en comparación con otros, sino también en comparación con sus propios resultados anteriores.

En 2006 participaron 51 países del mundo entero, miembros de la OCDE o países asociados, pero hubo poca participación de África y Asia. En América Latina participaron Chile, Argentina, Colombia, Uruguay, México y Brasil. Uno de los factores clave del interés que suscitan los informes es precisamente el gran número de países que participan. Otros factores son la calidad de las tareas en las que se basa 
la comparación y la elaboración estadística de todos estos datos. La recogida de datos se hace a través de un sistema sofisticado con múltiples "cuadernos" de dificultad equivalente para evitar el fraude.

Cuando se lanzó el programa PISA, ya se hablaba de una crisis en la educación en bastantes países occidentales. La escuela comprensiva y la nueva pedagogía no daban los resultados de convivencia y calidad que se esperaban. En España, muchas personas asocian este desarrollo con la LOGSE del año 1990 y en un país como Suecia ese mismo desarrollo empezó ya con una ley de 1969. Por eso, los informes PISA, que sólo dan cuenta de lo que ha sucedido durante las últimas décadas, no muestran más que "la punta del iceberg".

Pocas personas han leído más que el resumen de PISA, y hay buenas razones para ello: el volumen que recoge los resultados de 2006 es un texto largo, 397 páginas $^{4}$. Muchos profesores y periodistas no se dan cuenta de que las personas responsables de PISA pertenecen al gremio de los nuevos pedagogos a pesar de incluirse un ranking en el informe. La mayoría de los lectores buscan en primer lugar el ranking, pero los autores muestran su propia actitud frente al ranking, "escondiéndolo" dentro de una masa de otros datos. El informe habla mucho del entorno socioeconómico del alumno, pero no del esfuerzo ni de las exigencias. Se quiere "elevar el rendimiento global de los estudiantes y, al mismo tiempo, amortiguar el impacto que el grupo socioeconómico puede tener en dicho rendimiento, promoviendo así una distribución

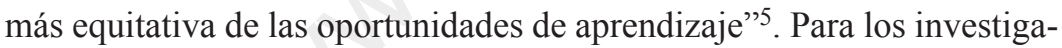
dores, la igualdad es una meta tan importante como el conocimiento. El texto habla de "distribuir" los conocimientos como si fueran una mercancía. No se menciona que los países desarrollados han visto aparecer a grupos de alumnos a los que se les ofrece la oportunidad de aprender, pero que responden con indiferencia o con actos de vandalismo ante una oferta que no les interesa. Los investigadores no tienen nada que decir sobre los problemas de conducta, pero critican la repetición de curso y consideran negativa la libertad de elegir el colegio. También critican a los colegios concertados, insinuando que obtienen buenos resultados únicamente por dirigirse a grupos de alumnos preseleccionados. La impronta igualitaria en los informes PISA es fuerte ${ }^{6}$. Además, los autores de mañana.

${ }^{4}$ OCDE, Informe PISA 2006. Competencias cientificas para el mundo

5 Ibídem, p. 29.

${ }^{6}$ Ibídem, pp. 285 y 231. 
evitan palabras como "conocimiento", prefiriendo la de "competencia". "Competencia" suena como algo práctico y orientado hacia el futuro, mientras que "conocimiento" podría sonar como algo tradicional y, por eso, no tan atractivo. Además, "competencia" hace pensar en una preparación para el mercado laboral y la OCDE es una organización de colaboración económica. Otro ejemplo es que los investigadores dicen querer ir más allá de la memorización ${ }^{7}$. Los nuevos pedagogos han hecho campaña durante décadas contra la memorización y es verdad que algunas tradiciones pedagógicas se apoyan mucho en la memorización, pero actualmente en los países occidentales el problema podría ser lo contrario: hace falta memorizar más para poder desarrollar los conocimientos y las competencias.

El informe PISA de 2006 habla poco de los profesores y no menciona la palabra "instrucción”, lo cual está también en consonancia con la idea de la nueva pedagogía de que los alumnos deben buscar la información por su cuenta y los profesores sólo actuar como facilitadores. No fue hasta la publicación del informe McKinsey que los datos recogidos por PISA fueron utilizados para estudiar el efecto de la calidad de los profesores. Las recomendaciones del informe McKinsey son claras: conseguir que los mejores estudiantes se dediquen a la enseñanza, convertirlos en buenos instructores y asegurarse de que la buena enseñanza llegue a todos los alumnos. A propósito de la igualdad, el informe McKinsey dice de manera contundente que lo que más contribuye a la igualdad es darles a todos los alumnos buenos profesores, una idea no expresada en el informe PISA.

Además del informe PISA, los investigadores de la OCDE publicaron en 2008 dos tomos sobre los directores de colegios en diferentes países. Los investigadores recomiendan el uso de equipos directivos y no de directores individuales. Su ideal son las soluciones colectivas también para los directores de los colegios. No discuten el papel del director como modelo o referencia moral e intelectual para profesores y alumnos.

Sin embargo, en el segundo volumen del informe de la OCDE sobre los directores de los colegios, hay un "estudio de caso" sobre Finlandia ${ }^{8}$. Según las declaraciones de los profesores finlandeses entrevis-

${ }^{7}$ Ibídem, p. 9.

${ }^{8}$ Beatriz Pont et al., Improving School Leadership. Case Studies on System Leadership, 2008. 
tados, el éxito educativo del país está relacionado con la buena calidad de los profesores y el respeto de todos los ciudadanos por los conocimientos, es decir, no con la nueva pedagogía. Los entrevistados hablan de la confianza que se tiene en los profesores y también del esfuerzo por evitar todo tipo de burocracia. Adjudican el éxito finlandés a una dirección estable, un liderazgo moral y la ausencia de cambios bruscos. Los profesores utilizan formas de trabajo tradicionales más que técnicamente innovadoras y declaran que trabajan con métodos que conocen a fondo y en los que tienen confianza. Añaden que se interesan por lo que funciona en el aula y no por las publicaciones pedagógicas. Utilizan una y otra vez palabras como "colaboración", "responsabilidad", "participación", "darse metas" y "evaluar los logros". Los investigadores que redactan el texto mencionan estas declaraciones, pero sin destacarlas.

Se puede observar un contraste entre los economistas de la OCDE, que promocionan la excelencia a través del benchmarking y del ranking, y los pedagogos al servicio de la misma organización que enfocan la igualdad. El informe McKinsey significa una clara crítica contra la interpretación de los pedagogos de los datos en los informes PISA que apuntan a lo socioeconómico y no a la calidad de la enseñanza como explicación del buen resultado de ciertos alumnos.

Además, la OCDE publica una vez al año unas estadísticas sobre el mundo de la educación, Educación at a Glance. Un educador nota enseguida que el informe está realizado por economistas porque lo que les interesa es si los países tienen una mano de obra calificada y la relación entre inversión en la educación, el nivel de empleo y los niveles de los salarios; no les interesa el contenido de la educación. En Education at a Glance 2008 se constata que cada vez hay más puestos de trabajo que exigen niveles cada vez más altos de calificación, a la vez que disminuyen los puestos de trabajo poco calificados. Las personas con más educación tienen menos desempleo y retrasan más el momento de jubilarse. Se examina la razón profesor-alumno, constatando que varía mucho y que hay países como Finlandia que obtienen buenos resultados con grupos pequeños y otros, como Corea del Sur, que obtienen buenos resultados con grupos grandes ${ }^{10}$. En cuanto a la inversión, es importante cierta inversión de base, pero, entre los países que ya invierten bastan-

\footnotetext{
${ }^{9}$ Ibídem, pp. 77-87.

${ }^{10}$ OCDE, Education at a Glance, 2008.
} 
te, la calidad no aumenta con más inversión ${ }^{11}$. Otro dato interesante es que muchos países han aumentado su inversión en educación, pero, en promedio, los resultados de comprensión lectora no han mejorado ${ }^{12}$. Tampoco hay una relación clara entre el resultado y el número de horas ofrecidas a los alumnos ${ }^{13}$.

Una manera de comentar los informes PISA es compararlos con un estudio recién salido en Francia ${ }^{14}$. Un director de colegio se describe a sí mismo como progresista y vinculado a Philippe Meirieu. Para entender esta referencia es necesario saber que Meirieu es el "padre" de la nueva pedagogía en Francia y ocupa una posición similar a la de Álvaro Marchesi en España. El profesor en cuestión utiliza el ejemplo de Finlandia para subrayar la igualdad entre los alumnos y las atractivas formas de trabajo que califica de democráticas y libres. No menciona la calidad de los profesores ni tampoco el respeto por los estudios. Su actitud frente a los éxitos finlandeses es la misma que la de los autores de los informes PISA: los investigadores admiran más la igualdad que la calidad y no hablan del esfuerzo ni de los alumnos, como si los éxitos se hubieran logrado por arte de magia.

PISA es influyente. Cuando la Dirección General de las Escuelas suecas, dominada por personas que adhieren a la nueva pedagogía, explica el resultado de PISA 2003, no parece preocuparse por la caída de los resultados. Dice que, en el currículo sueco, se enfatizan los valores y esto no se mide en PISA. No se comenta que, a pesar de publicar la Dirección tantos estudios, éstos no han contribuido a mejorar la calidad. En el informe siguiente sobre los resultados de PISA de 2006 sí se constata que bajan los resultados, que la dispersión de los resultados es mayor, que les va peor tanto a los mejores alumnos como a los más flojos. Ahora se constata: "Hay un consenso sobre la necesidad de mejorar los resultados de aprendizaje de la escuela básica" 15 . Se califican de "significativos" los cambios negativos en comprensión lectora y matemáticas ${ }^{16}$. Se constata

${ }^{11}$ Ibídem, pp. 202 y 305.

12 Ibídem, p. 216.

${ }^{13}$ Ibídem, p. 412.

${ }^{14}$ Paul Robert, La Finlande: Un Modèle por la France? Les Secrets de la Réussite, 2008.

15 OCDE, PISA 2003. Svenska femtonåringars kunskaper och attityder $i$ ett internationellt perspektiv, 2004, p. 10.

${ }^{16}$ OCDE, PISA 2006. 15-åringars förmåga att förstå, tolka och reflektera-naturvetenskap, matematik och läsförståelse, 2007, p. 116. 
que, además, hay una gran diferencia entre los resultados de los alumnos inmigrantes y de los no inmigrantes.

\section{Algunos de los resultados de PISA en tablas}

A continuación se va a dar cuenta de algunos resultados de PISA. Primero hay unas tablas que insertan los logros de Finlandia entre otros países más o menos exitosos. Después se describe la relación entre los países latinoamericanos que participaron en 2006 en PISA.

TABLA N ${ }^{\circ}$ 1: $\quad$ RESULTADO DE PISA EN MATEMÁTICAS

\begin{tabular}{lll}
\hline 2000 & 2003 & 2006 \\
\hline & & \\
1. Japón 557 & 1. Finlandia 544 & 1. Finlandia 548 \\
2. Corea del Sur 547 & 2. Corea del Sur 542 & 2. Corea del Sur 547 \\
3. Nueva Zelanda 537 & 3. Países Bajos 538 & 3. Países Bajos 531 \\
4. Finlandia 536 & 4. Japón 534 & 4. Suiza 530 \\
5. Australia 533 & 5. Canadá 532 & 5. Canadá 527 \\
6. Canadá 533 & 6. Bélgica 529 & 6. Japón 523 \\
14. Suecia 510 & 14. Suecia 509 & 15. Suecia 502 \\
21. España 476 & 23. España 485 & 24. España 480 \\
\hline
\end{tabular}

TABLA N ${ }^{\circ}$ :

RESULTADO DE PISA EN CIENCIAS NATURALES

2000

2003

2006

1. Corea del Sur 552

2. Japón 550

3. Finlandia 538

4. Gran Bretaña 532

5. Canadá 529

6. Australia 528

7. Nueva Zelanda 528

8. Austria 519

10. Suecia 512

19. España 491
1. Finlandia 548

2. Japón 548

3. Corea del Sur 538

4. Australia 525

5. Países Bajos 524

6. República Checa 523

7. Nueva Zelanda 521

8. Canadá 519

12. Suecia 506

21. España 487
1. Finlandia 563

2. Canadá 534

3. Japón 531

4. Nueva Zelanda 530

5. Australia 527

6. Países Bajos 525

7. Corea del Sur 522

8. Alemania 516

16. Suecia 503

23. España 488 


\begin{tabular}{lll}
\hline 2000 & 2003 & 2006 \\
\hline & & \\
1. Finlandia 546 & 1. Finlandia 543 & 1. Finlandia 546 \\
2. Canadá 534 & 2. Corea del sur 534 & 2. Canadá 534 \\
3. Nueva Zelanda 529 & 3. Canadá 528 & 3. Nueva Zelanda 529 \\
4. Australia 528 & 4. Australia 525 & 4. Australia 528 \\
5. Irlanda 527 & 5. Nueva Zelanda 522 & 5. Irlanda 527 \\
6. Corea del Sur 525 & 6. Irlanda 515 & 6. Corea del Sur 525 \\
7. Reino Unido 523 & 7. Suecia 514 & 7. Reino Unido 523 \\
8. Japón 522 & 8. Países Bajos 513 & 8. Japón 522 \\
9. Suecia 516 516 & 9. Bélgica 507 & 9. Suecia 519 \\
18. España 593 & 22. España 481 & 18. España 493 \\
& & \\
\hline
\end{tabular}

TABLA No 4 :

RESULTADOS DE LOS PAÍSES LATINOAMERICANOS EN PISA 2006

\begin{tabular}{lll}
\hline Matemáticas & Ciencias naturales & Comprensión lectora \\
\hline & & \\
28. Uruguay 427 & 31. Chile 438 & 21. Chile 442 \\
33. Chile 411 & 34. Uruguay 428 & 25. Uruguay 413 \\
34. México 406 & 40. México 410 & 26. México 410 \\
38. Argentina 381 & 42. Argentina 391 & 32. Brasil 393 \\
39. Colombia 370 & 43. Brasil 390 & 34. Colombia 385 \\
40. Brasil 370 370 & 44. Colombia 388 & 36. Argentina 374
\end{tabular}

\section{Breve historia de Finlandia}

Para entender la educación finlandesa de hoy es importante saber algunos datos sobre la historia del país. Ésta se puede dividir en tres fases: la fase sueca, la fase rusa y la fase finlandesa ${ }^{17}$. La actual Finlandia fue cristianizada en el siglo XII y, desde esta época también, fue una región de Suecia. En 1527, con la Reforma, se convirtió oficialmente al luteranismo junto con el resto de Suecia. La iglesia y el Estado mostraron desde el principio interés por la educación popular, siendo el centro erudito Turku, una ciudad situada en la costa suroeste del país. Se estudiaba en primer lugar el latín.

${ }^{17}$ Véase Martti T. Kuikka, A History of Finnish Education, 1992. 
La época rusa empezó en 1809 cuando Suecia perdió Finlandia en una guerra contra Rusia. Esto coincidió en el tiempo con un movimiento en toda Europa de nacionalismo romántico. En Finlandia se promovía el finés y se daba importancia a la poesía popular y a los cuentos populares. La ocupación rusa resultó un impulso para promover una cultura finlandesa como una manera de reunir a los ciudadanos alrededor del movimiento nacionalista. Un educador importante del siglo XIX, Snellman, intentó apartar a los finlandeses a la vez de Suecia y de Rusia. El centro de este movimiento era Turku. Desde esta época, se generalizó entre los finlandeses la convicción de que no pueden conseguir nada por la fuerza, por ser tan pocos; tienen que hacerse valer por el esfuerzo en común y por la cultura ${ }^{18}$.

En conexión con la Revolución rusa y la caída del zarismo, Finlandia logró su independencia en 1917, pero estalló al mismo tiempo una guerra civil. Después de recobrada la tranquilidad, tocaba organizar el nuevo país que era un país agrario bastante pobre. Durante la segunda guerra mundial, Finlandia fue atacada dos veces por la Unión Soviética, que quería incorporarla otra vez dentro de sus fronteras. Finlandia resistió heroicamente pero, para conservar su independencia después de la guerra, tuvo que ceder territorios y pagar sumas importantes a la Unión Soviética. Hasta la disolución de la Unión Soviética, los políticos finlandeses fueron siempre muy cautos en sus relaciones internacionales para no tener "problemas" con su poderoso vecino. Los finlandeses participaron durante este período con mucho entusiasmo en los proyectos de colaboración entre los países nórdicos; querían dejar en claro que su identidad era escandinava.

Aproximadamente hasta 1960, Finlandia era un país agrario relativamente pobre con un $35 \%$ de la población ocupada en la agricultura; esta situación llevó a una fuerte emigración en primer lugar hacia Suecia y Canadá. Se calcula que se fueron durante un período bastante reducido 300.000 personas de una población de 4,5 millones. En los años 60 empezó una transformación muy rápida y muy profunda de Finlandia ${ }^{19}$. A golpe de trabajo y ahorro, Finlandia mejoró su situación económica, entró en la Unión Europea en 1995 y a la zona euro en 1999. Durante la segunda parte de los años 90 y después de 2000, Finlandia

${ }^{18}$ Ritva Jakku-Sihvonen y Hannele Niemi (eds.), Education as a Societal Contributor, 2007, pp. 73-75.

19 Ibídem, p. 77. 
ha vivido un boom económico; antes no aceptaba a inmigrantes por ser un país de emigración; ahora hay cada vez más inmigrantes en primer lugar de Rusia, de los países de Europa oriental y de países como Afganistán, Irán e Irak. Sin embargo, el número total de inmigrantes es todavía insignificante.

En 2010, los cinco millones de habitantes que tiene Finlandia conforman una población muy homogénea. La lengua es el finés, una lengua fino-ugria no indoeuropea, emparentada con el estonio y el húngaro. A mediados del siglo XIX había un número similar de hablantes de sueco y de finés en Finlandia y el sueco sigue siendo una lengua cooficial, pero la población suecoparlante ha ido reduciéndose como resultado de los matrimonios mixtos y de la emigración a Suecia. Actualmente los hablantes de sueco son un 5\% y tienen sus propias escuelas y su propia formación docente, concentradas en la zona de Helsinki y en la costa oeste, en las ciudades de Turku y Vasa.

Como Singapur y Hong-Kong, Finlandia tiene que vivir del talante industrioso de sus habitantes. La empresa finlandesa más conocida en estos momentos es seguramente Nokia, la empresa de telecomunicaciones $^{20}$. La historia de la empresa es típica de la Finlandia de hoy que ya no es un país agrícola. La empresa se fundó en 1865 y entonces se concentraba en la madera y en la energía. A principios del siglo XX abrió una fábrica de goma y otra de cables. En 1987-1992, la empresa compró fábricas de televisores en varios países, una mala inversión que hundió a la empresa en una profunda crisis, pero sobrevivió trasladando sus actividades al campo de las telecomunicaciones. Cuando el historiador de la empresa intenta explicar el éxito, habla de la desregularización temprana del mercado de telecomunicaciones en Finlandia dentro de un marco legal adecuado y estable, pero también apunta a la innovación técnica y la audacia comercial. Para la historia de Nokia fue importante la disolución de la Unión Soviética, porque la empresa perdió de golpe sus contratos de larga duración con aquel país y tuvo que buscarse otros mercados. Cada vez hay menos acciones de Nokia en manos finlandesas, pero la empresa tiene su sede en Helsinki y los jefes máximos son finlandeses. Sin embargo, el lenguaje de comunicación de la empresa es el inglés y la empresa tiene fábricas y centros de diseño y de innovación en varios continentes.

${ }^{20}$ Véase Martti Häikio, Nokia - vägen till framgång, 2003. 


\section{La educación finlandesa}

Cuando algunos pedagogos finlandeses intentan identificar los rasgos salientes en la política educativa finlandesa mencionan el fuerte énfasis en la igualdad y, como consecuencia, una fuerte apuesta por el apoyo pedagógico a los alumnos con problemas. Se parte de la idea de que todos pueden lograr buenos resultados. El enfoque se puede llamar "ingeniería social", aunque ese término no se utiliza. No se permite que diferencias sociales o genéticas influyan más que lo inevitable en los resultados. En 1967, se tomó la decisión de introducir una escuela comprensiva de nueve años y esto fue el primer comienzo de una reforma educativa desde la primaria hasta la universidad, una reforma basada en una enseñanza estatal y gratuita. En las comparaciones de los años 60, Finlandia tenía una posición intermedia, sin embargo al comienzo de los 2000 se encontraba en la cumbre internacional. En 2000, Finlandia empezó a organizar sus carreras universitarias según la norma europea "de Bologna".

Actualmente, la escuela es obligatoria, gratuita y "comprensiva". La educación empieza a los siete años, es decir, relativamente tarde. Hace poco se introdujo también un año preescolar obligatorio desde los seis años de edad. Después de terminar el noveno a los 16 años de edad, el alumno que lo necesite puede quedarse otro año más en la escuela comprensiva. Después de la escuela obligatoria hay una secundaria superior de tres años, que corresponde en Chile a la enseñanza media, un nivel no obligatorio. Más de la mitad de los alumnos estudian carreras de formación técnica y existen "pasarelas" para el alumno que quiera cambiar de orientación. La formación técnica también tiene una continuación en la educación superior. Para obtener una plaza en la universidad hay que superar un examen nacional y después, además, casi siempre una prueba de selección, porque hay más candidatos que plazas. Este numerus clausus es muy importante para explicar la asiduidad de los alumnos con aspiraciones universitarias. Los salarios en Finlandia son más altos que los chilenos pero también son más altos los costes de vida y los impuestos. Un profesor de primaria empieza con un salario de $€ .2300$ y un profesor de matemáticas y ciencias naturales de la enseñanza media empieza con un $€ 2.500$ y puede terminar ganando $€ 4.000$. El promedio de los salarios es de unos $€ 2.600$. 
Finlandia tiene buenos docentes y uno de los secretos es que puede haber hasta diez solicitantes para cada plaza en la formación docente. La profesión atrae a los jóvenes inteligentes y ambiciosos, a pesar de que el salario de los profesores finlandeses es bueno pero no generoso. Los docentes reciben parte de su recompensa en forma inmaterial, sintiéndose útiles y respetados.

Finlandia tiene un marco curricular nacional muy concreto que tiene fuerza de ley; los profesores están obligados a enseñar el contenido del currículo. Entre otras cosas, el currículo contiene descripciones relativamente detalladas de lo que debe saber hacer un estudiante de cierto grado con buena nota. El currículo se caracteriza por el entusiasmo por la educación, la fe en los alumnos y en los profesores y, de manera general, la sensatez.

El "milagro" finlandés se explica también por el énfasis en la socialización de los alumnos y la no aceptación de que un alumno moleste a los demás o no estudie. Está prevista una serie de medidas para enfrentar los problemas de conducta y de aprendizaje. Se agrupa a los alumnos inmigrantes, que no dominen todavía el finés, en centros especiales. Hay relativamente pocos psicólogos y trabajadores sociales en la escuela finlandesa.

El sistema finlandés es relativamente barato, porque se dan relativamente pocas horas durante relativamente pocos años. Se pagan salarios suficientes, pero no muy altos, a profesores que están bien preparados y trabajan mucho: a la vez, también los alumnos trabajan relativamente mucho y no se tolera que alguien interrumpa o moleste cuando se está trabajando. En tres palabras, el sistema finlandés es bueno, bonito y barato.

\section{Marco curricular para la escuela obligatoria}

El currículo de 2004 habla constantemente de lo que el alumno debe saber y debe saber hacer. Entre las metas se incluye mostrar una actitud responsable y respetuosa; se habla de desarrollar la identidad finlandesa y europea del alumno ${ }^{21}$. Además, una de las metas es que el alumno entienda cuáles son sus lados fuertes y menos fuertes. Los profesores tienen la responsabilidad de solicitar enseñanza especial para

${ }^{21}$ Ministerio de Educación de Finlandia, National Core Curriculum for Basic Education 2004, 2004. 
los alumnos que la necesiten; también ayudan a orientar a los alumnos de cara a los estudios postobligatorios.

La enseñanza de la lengua ocupa la mitad de las páginas del currículo. El gran número de páginas sobre la lengua se explica por la división de la materia en finés, sueco y lapón como lengua materna o como lengua extranjera. En la descripción se utiliza el marco europeo de idiomas. Las pocas personas que hablan el lapón viven dispersas en zonas extensas y, además, la lengua se divide en tres variantes diferentes.

Para todos los grados y materias se especifica claramente lo que debe saber hacer el alumno. En lenguaje, después del primer grado, el alumno debe haber aprendido a escuchar atentamente, formular preguntas y contestarlas. Debe saber trabajar sobre lo que ha oído, visto y leído. Debe haber trabajado intensamente sobre la correspondencia entre sonido y letra, y haber practicado el leer y el escribir. Debe saber usar las mayúsculas y las minúsculas y separar las palabras. Después del segundo grado, debe saber escribir, y no sólo con letra de imprenta, y debe dominar la ortografía de las palabras usuales. Después del tercer grado debe saber leer con fluidez y hablar sobre lo leído y, por ejemplo, saber anticipar lo que va a suceder en un texto, resumirlo y comentarlo. Se habla de estrategias para referirse a actuar con responsabilidad, aprender palabras y consultar diccionarios, es decir, lo que se llama "estrategias" es lo que se solía llamar buenas costumbres de estudio. En la secundaria los alumnos deben saber describir un texto desde el punto de vista de la sintaxis y del vocabulario.

En las otras materias, el programa es igual de explícito. Para las matemáticas, se insiste en encontrar similitudes, diferencias, regularidades, causas y efectos. Los alumnos deben aprender a argumentar para apoyar sus propuestas. Se subraya la importancia de poder aplicar reglas y seguir las indicaciones del profesor o del libro. Para los grados tercero o quinto se insiste en que el alumno debe ser capaz de realizar un trabajo prolongado y concentrado, como también ser capaz de trabajar en equipo. Así se sigue con biología, química, física, ciencias sociales, lenguas extranjeras, historia, religión, deporte, salud, arte, música, taller de madera y de textil y hogar. En todas las materias, los alumnos deben aprender lo que es tradicional en el país. En literatura: las obras literarias finlandesas más famosas. En religión: el luteranismo con la opción de la fe ortodoxa y la ética. En música, cantar las canciones folklóricas y los 
salmos tradicionales y conocer a los principales compositores finlandeses. En arte, conocer a artistas y a arquitectos finlandeses. En deporte: nadar, esquiar y patinar. En hogar: los platos finlandeses tradicionales.

En la escuela básica, los municipios tienen la obligación de ofrecer ciertas materias y cierto número de horas pero pueden añadir materias y horas por encima de este mínimo. Pueden organizar como quieran las pruebas, las notas, la enseñanza especial y los contactos con las empresas locales. Así es como combinan los finlandeses la centralización y la descentralización.

\section{El punto de vista de una profesora finlandesa}

Todo esto viene ilustrado de manera concreta por las comparaciones de una profesora de primaria finlandesa suecoparlante. Formada en Finlandia, trabajó primero unos años en Finlandia y después se trasladó a Suecia a trabajar. Comenta sus experiencias de una manera gráfica $^{22}$. Empieza diciendo que cuando trabajaba en Finlandia quería más libertad, pero después de haber trabajado en Suecia ve la importancia de tener mucha estructura. Ve bastantes diferencias; para ella, la clave del éxito finlandés es la sencillez.

- En Finlandia, las clases son de 45 minutos y los alumnos aprenden desde el primer día a estar quietos y a escuchar. En Finlandia se introducen rutinas firmes. Los alumnos tienen bastantes tareas y pruebas. El docente es el líder indiscutido del aula. El enfoque está en las destrezas básicas y en la enseñanza especial. El profesor de enseñanza especial tiene la responsabilidad de los alumnos de enseñanza especial, lo que resulta una tarea menos para el otro profesor.

- Ya que el currículo incluye una descripción de lo que debe saber un buen alumno, todos, profesores, alumnos y padres, saben de manera concreta lo que se espera de un joven. Los profesores suelen usar manuales y por eso pueden concentrarse en transmitir el conocimiento y no en producir materiales. Hay pruebas continuamente y así los alumnos se acostumbran a ser evaluados y a evaluarse ellos mismos. Ven claramente lo que les falta aprender.

- El director del colegio es quien toma las decisiones administrativas, organiza el horario y es el responsable de realizar las compras de

${ }^{22}$ Åsa Sourander, Sisu i klassurmmet. Fem framgångsfaktorer från Finland som ger resultat, 2009. 
los manuales. Así, no se necesita a tantos grupos de trabajo. Los padres tienen mucha confianza en la escuela y, ya que la actividad de la escuela no está cuestionada, el resultado es un ambiente poco estresado.

- En general, se da el mismo programa a todos. Hay poca adaptación a las necesidades de cada uno, sino que todos deben aprender lo que se enseña. Se trata de una enseñanza organizada por el docente y los alumnos apenas pueden opinar sobre lo que se va a hacer o no. El currículo nacional tiene carácter de ley y el profesor tiene que dar ese contenido para asegurar a todos su derecho a la educación. Desde tiempos inmemoriales la escala de notas va desde el 4 (suspenso) hasta el 10. Los alumnos reciben notas cada año, pero también unas notas preliminares tres meses antes del final del curso. En la primaria, en algunos municipios se dan notas orales; cada municipio decide por su cuenta. Toda la enseñanza es gratuita, incluyendo el año preescolar a los seis años de edad.

- La enseñanza especial tiene varias formas. El alumno puede quedarse con su grupo, saliendo del aula durante algunas horas por semana para trabajar con un profesor especial. También se da el caso de que el profesor de enseñanza especial entre al aula para ayudar allí mismo al alumno. Alguna vez la enseñanza especial puede también significar ir a otro colegio en el municipio en el que se concentra cierta enseñanza especial. Finalmente, puede significar estudiar en un colegio que sólo tiene enseñanza especial.

- Los docentes son pagados por las horas que dan; si dan más horas, aumenta su salario. En promedio, un docente enseña 25 clases por semana. Los alumnos tienen deberes desde el lunes hasta el jueves. Cuando la profesora describe un día normal, muchos docentes suecos reconocen la situación de antes de la introducción de la nueva pedagogía.

La profesora comenta como fundamental que en Finlandia se acepte la autoridad: los docentes aceptan seguir el currículo, y tanto los alumnos como los padres aceptan la autoridad del docente para organizar la actividad. El nuevo marco curricular nacional de 1994 aumentó la libertad del profesor, pero empezaron a aparecer grandes diferencias entre los colegios $\mathrm{y}$, por eso, se introdujo relativamente rápido otro currículo, el que se acaba de describir, de 2004, que disminuyó esta libertad. Con el nuevo currículo más preciso, un alumno puede mudarse de un municipio a otro sin perder tiempo. 
Las notas incluyen apreciaciones sobre la conducta del alumno. Para los alumnos de todas las edades están programadas conversaciones con los padres. En esas conversaciones se habla del aprendizaje, de la conducta y de las metas del alumno para el futuro próximo. En la evaluación de la conducta, diferentes municipios siguen diferentes pautas. Algunos aplican una escala de 1 a 5 para expresar si el alumno respeta a los demás y si sabe controlar su comportamiento y sus palabras. También se evalúa si sabe planificar su trabajo y si sabe evaluar su propio rendimiento. Se considera importante que el alumno aprenda a entender cómo es él mismo. Existe una escala de medidas para los alumnos que no respeten las reglas, como quedarse en el colegio después de la jornada escolar, una amonestación escrita y, al final de la escala, la exclusión durante tres meses.

En la primaria, el aprendizaje de la lectura se hace respetando cierto orden entre las letras y los alumnos deben escuchar, repetir, leer, escribir, recortar, dibujar, tanto la mayúscula como la minúscula. Cuando hay lectura, el maestro suele empezar leyendo al grupo, después todos hablan sobre el texto. El paso siguiente es que los alumnos lean juntos el texto muchas veces. Finalmente, a cada alumno le es asignada una tarea de lectura. El profesor intenta escuchar varias veces por semana cuando el alumno lee el trozo que ha practicado en casa. En Finlandia, un profesor sigue durante bastante tiempo la rutina del aprendizaje básico de leer, lo cual ahorra tiempo, porque evita que haya alumnos que no consigan aprender. En Suecia, cada alumno es invitado a aprender a su manera. Tener que organizar sus propios estudios les quita tiempo a los alumnos, considera la profesora.

La profesora cuenta un método específico que ha inventado para controlar si los alumnos han trabajado con la tarea del día por ejemplo en ciencias sociales. Divide a los alumnos en grupos de cuatro y les pide que dibujen un "mapa de pensamiento", explicando lo aprendido. Todos los alumnos deben dibujar su propio mapa. Después de seis minutos, la profesora reorganiza a los alumnos en otros grupos y todos deben comparar su mapa con los mapas de los nuevos compañeros, mejorando su propio mapa. Así, están activos todos, discutiendo. Para activar a los alumnos que están leyendo, utiliza un ejercicio sencillo que consiste en preguntarles qué sucedería si se quitara cierto episodio o a cierto personaje o, al revés, si se añadiera algo. 
La comparación con Finlandia permite a la profesora observar que, en Suecia, bastantes niños carecen de la costumbre de escuchar atentamente, porque siempre han trabajado de manera individual y a su propio ritmo. Ella tiene que insistir para que la escuchen con atención y no tener que repetir lo mismo varias veces. En el colegio sueco donde trabaja ahora se organizan muchas excursiones y visitas, pero la profesora considera que perjudican la rutina necesaria para el aprendizaje.

Insiste en que hay que describir claramente a los alumnos lo que se considera un buen comportamiento. Muchas veces, los adultos creen que los niños saben cómo deben comportarse, pero no siempre es así. Es necesario decirles que hay que estar silencioso cuando habla otra persona, que hay que pedir la palabra y que no se puede hacer ruido de ningún tipo durante la lectura de otra persona o durante una función de teatro.

\section{El análisis oficial finlandés del "milagro"}

En un análisis del Ministerio de Educación, los autores se felicitan de que Finlandia tenga poca diferencia entre las escuelas. Apenas hay diferencias regionales, sociales o de género. Afirman una vez más que Finlandia da mucha importancia a la igualdad pero, además, celebran que haya logrado los buenos resultados sin dedicar sumas desorbitantes para conseguir esta meta. Hoy en día, todos los alumnos, padres de alumnos y profesores son productos de la escuela comprensiva y ésta no está cuestionada. Les va algo menos bien a los pocos inmigrantes, pero es la opinión del ministerio que, si logra buenos resultados el grupo mayoritario, esto va a resultar una ventaja también para los que quieran instalarse en el país ${ }^{23}$.

En PISA 2006, el enfoque han sido las ciencias naturales y Finlandia ha logrado resultados por encima de los otros países escandinavos. El resultado se ha logrado asegurándose de que casi no hay estudiantes muy malos y que los buenos son muchos. Finlandia ha conseguido que los alumnos se interesen por las ciencias naturales y que vean que las ciencias naturales son importantes para el futuro del país. Las ciencias naturales se enseñan como materias separadas y con profesores

${ }^{23}$ Jarkko Hautamäki et al., PISA 06. Analyses, Reflections, Explanations, 2008, p. 49. 
especializados. No hay ningún problema grave para conseguir profesores calificados y sólo un 10\% de los profesores que enseñan ciencias naturales a tiempo completo no tiene un examen completo.

En ciencias naturales los alumnos tienen tareas para la casa, tareas que les ocupan unas dos horas por semana. Las diferentes regiones tienen bastante libertad en cuanto a la organización de la educación, pero no en cuanto al currículo. Oficialmente, en los municipios se usa poco la división formal entre grupos de diferente nivel, streaming pero se da en una tercera parte de los municipios, sobre todo en matemáticas y en lenguas extranjeras; además, existen maneras informales de agrupar a los alumnos según su nivel ${ }^{24}$.

Los profesores finlandeses son bastante tradicionales en su manera de organizar el trabajo en el aula. Usan sobre todo la enseñanza "de cátedra" con un profesor explicando un tema al grupo entero. En las ciencias naturales, las clases magistrales se combinan con ejercicios prácticos. Los estudiantes afirman que pueden participar y discutir dentro del marco organizado por el profesor. El profesor explica, pero las conclusiones se sacan entre todos. Hay a la vez instrucción y trabajo propio. Por lo visto, ese tipo de organización da mejor resultado que cuando los estudiantes organizan solos su trabajo. Sería una equivocación decir que los alumnos están pasivos en el modelo finlandés, ya que escuchan, intentan aprender, realizan experimentos y sacan conclusiones $^{25}$.

Para explicar el éxito, el informe menciona también que ha habido consenso político y cultural entre los ciudadanos alrededor de la política educativa. Se prefiere una educación estatal igual para todos y que los cambios se introduzcan paso a paso y no de golpe. Los finlandeses parecen contentos con el equilibro entre centralismo y regionalismo.

Los expertos finlandeses enfatizan que Finlandia se caracteriza por una buena enseñanza dispensada por profesores especializados. Cuando los finlandeses comparan su escuela comprensiva con la sueca, consideran que la suya está más enfocada en la socialización de los alumnos que en los fines políticos. Los profesores finlandeses tienen actualmente una mejor formación en las materias que sus colegas nórdicos en general. También se han producido buenos manuales basados en el currículo. Los finlandeses no tienen exámenes obligatorios en la

\footnotetext{
${ }^{24}$ Ibídem, pp. 79-97 y 140.

${ }^{25}$ Ibídem, pp. 101-105.
} 
escuela comprensiva, pero utilizan pruebas para comprobar el nivel de manera general. Tampoco publican los resultados de los diferentes colegios como se hace en muchos países. Un comentario podría ser que no se controla tanto a los profesores, porque se confía en ellos. Así, el país se ahorra el gasto de pruebas nacionales en la escuela comprensiva y aun así logra buenos resultados. Como contraste, en la secundaria superior, las pruebas nacionales juegan un papel importante.

Los análisis de las respuestas de PISA de los alumnos finlandeses destacan que el fuerte de los jóvenes es usar el sentido común. No brillan tanto en los aspectos más teóricos. Son ayudados por su buena comprensión lectora y por su buen manejo de la aritmética básica. Todos los comentaristas subrayan que no se "permite" que un alumno no lea bien. Si alguien va a la zaga de su grupo, en seguida se le organiza un intensivo programa de apoyo. Los comentaristas también subrayan que los alumnos finlandeses no deben ser considerados como unos atletas intelectuales, porque tampoco ellos pueden con todos los ejercicios; su éxito está en ser mejores que los otros. Lo que explica el buen resultado es que los alumnos han aprendido desde el comienzo a aceptar una ética de trabajo; también importa, pero menos, que suele haber unos 20 alumnos por grupo, variando el número de alumnos entre por ejemplo 12 y 30 .

En 2006, un $21 \%$ de los estudiantes recibieron apoyo a través del sistema de enseñanza especial. De ellos, un $25 \%$ ha estudiado en escuelas especiales; un $33 \%$ ha recibido la ayuda en clases especiales en escuelas corrientes. Ahora hay un movimiento para integrar más en escuelas corrientes a los alumnos con problema y hasta el $43 \%$ podría estar integrado. Los educadores constatan que es un gran reto lograr eso, porque los que tienen problemas de aprendizaje tienden a acumular también otros problemas de carácter médico o social. Los alumnos muy buenos o hasta brillantes obtienen muy poca ayuda extra ${ }^{26}$. Como se ha dicho, el ethos escolar finlandés es igualitario. En los años 70 se hicieron varios experimentos con consejos escolares con una fuerte influencia de alumnos para convertir en más igualitaria la escuela. Sin embargo, esto hizo bajar los resultados y los finlandeses dieron marcha atrás, volviendo a insistir en los conocimientos como método para lograr una educación democrática.

${ }^{26}$ Ibídem, pp. 177-178. 
Para un observador externo podría parecer una paradoja que los alumnos no tengan muchas clases de matemáticas y aun así logren buenos resultados. Parece que el "secreto" es que, en todas las materias, los alumnos leen, escriben y sacan conclusiones. Los docentes insisten en resumir lo leído, identificar los hechos importantes del texto y preguntar a los alumnos por las intenciones de los personajes. Como en otros países, hay más interés por la lectura entre las chicas que entre los chicos, y se comenta que haría falta encontrar una "pedagogía para chicos". También en Finlandia, los alumnos de nivel social más elevado logran mejores resultados, pero la diferencia no es tan grande.

Desde la clase preescolar, los alumnos se acostumbran a estar en un ambiente escolar y a aceptar la organización del trabajo propuesta por los docentes. Es notable que se hable del año preescolar no como preparación a la escuela sino al aprendizaje. Los niños de seis años deben saber lo siguiente: 1. Entender la diferencia entre lo real y lo imaginario. 2. Tomar la responsabilidad de sus propias actividades y de la colaboración con otros. 3. Aceptar la necesidad de cambiar y desarrollarse. 4. Saber entrar en contacto con nuevas personas y nuevas actividades. 5. Acostumbrarse a buscar el sentido de las cosas como la actividad central del aprendizaje. 6. Entender que hay que ser flexible y hacer muchas cosas variadas en el proceso del aprendizaje $\mathrm{e}^{27}$.

Un ejemplo de una actividad para niños de seis años es mirar una casa de muñecas con mueblecitos y un plano en papel representando la misma casa. Los niños deben preguntarse en qué parte del plano se han de dibujar los mueblecitos. Deben identificar las ventanas y las puertas y las plantas de la casa. Para los alumnos de más edad se hacen también ejercicios en los que hay que ir de lo visible a lo general, de lo concreto a lo simbólico. Así, aprenden a usar el modelado como un instrumento de pensamiento y de planificación ${ }^{28}$.

\section{La formación docente}

En estos momentos, Finlandia tiene una de las poblaciones más educadas de Europa. Un 73\% de la población entre los 25 y los 64 años tiene estudios secundarios superiores y un 33\% tiene el nivel uni-

${ }^{27}$ Ritva Jakku-Sihvonen y Hannele Niemi (eds.), Education as a Societal Contributor, 2007, p. 119.

${ }^{28}$ Ibídem, p. 123. 
versitario o correspondiente ${ }^{29}$. Los docentes finlandeses deben tener todos un nivel universitario que corresponde a una licenciatura o un magíster, también los docentes del nivel preescolar. El curso directamente pedagógico consiste en un año de teoría y prácticas. Para ser profesor de educación especial la exigencia es tener un magíster. El profesor de los niveles superiores debe estudiar su materia principal durante por lo menos dos años, después estudia también dos materias más durante por lo menos un año. El desarrollo va hacia un menor número de períodos de prácticas pero un poco más largos, quizá de siete semanas. Hay "escuelas de prácticas" en conexión con las universidades y hay profesores especializados en acompañar a los futuros docentes cuando dan sus primeros pasos, y son puestos muy solicitados. Los estudiantes suelen formar parejas que se entreayudan y trabajan con el mismo profesor de prácticas. Las notas de los candidatos van del "aprobado", el "aprobado con una parte pendiente" al "suspendido". Se intenta trasmitir a los futuros docentes una actitud positiva frente a la investigación. En ningún lugar se expresa cierta ideología como el ideal de la formación docente. En los documentos estudiados, Finlandia aparece como un país ambicioso y con confianza en su capacidad de poder mejorar más todavía sus buenos resultados. Es un ejemplo de un círculo virtuoso.

Curiosamente, los documentos finlandeses dicen muy poco sobre la formación docente y la explicación podría ser que la calidad de la enseñanza no tiene tanto que ver con la formación en sí como con la selección de los candidatos. Hay muchísimos más candidatos que plazas. Este numerus clausus podría ser la parte más importante del "secreto" finlandés. Los que son aceptados son inteligentes, tienen una buena cultura general, un buen manejo del idioma y están muy motivados. La formación docente está descentralizada y cada región la organiza a su manera.

Un hecho curioso es que lo que dicen los pedagogos finlandeses es bastante similar a lo que se dice en los otros países escandinavos, así la diferencia no está tanto en el discurso como en la práctica. Los pedagogos finlandeses hablan también de constructivismo, de "aprender a aprender" y de "colocar al alumno en el centro del proceso de

29 Ritva Jakku-Sihvonen y Hannele Niemi (eds.), Research-based Teacher Education in Finland. Reflexions by Finnish Teacher Educators, 2006, p. 7. 
aprendizaje"30. Quieren unificar más las diferentes formaciones docentes y creen que los futuros docentes quieren más didáctica y menos énfasis en las materias. Subrayan la importancia del contacto frecuente entre los estudiantes y el mundo de la escuela. Trabajan con evaluaciones y con "carpetas", es decir, una presentación concreta de los diferentes trabajos realizados durante la formación. Se oye la misma terminología que se usa en otros países, pero el contenido se entiende de manera menos radical en Finlandia. Algunos comentaristas finlandeses con simpatía por la nueva pedagogía no saben qué decir del éxito de su propio país y suelen hablar de una contradicción en la escuela finlandesa: creen que el ambiente es democrático, pero la organización no lo $\mathrm{es}^{31}$. Parecen lamentar no poder mostrar una Finlandia más moderna.

Lo que debe contener una formación docente, según los finlandeses, es un conocimiento de la asignatura, conocimiento del currículo, conocimiento de las necesidades de los alumnos, conocimiento sobre cómo se aprende y un conocimiento pedagógico general ${ }^{32}$. Los profesores que deben orientar a estos futuros docentes constatan que la práctica tiende a no corresponder a la teoría pedagógica y que hay poca investigación sobre cómo se debe orientar a un futuro docente. Por eso, se atienen a lo concreto, discuten lo que ha pasado en el aula y basan su ayuda en escuchar, conversar y construir una confianza entre el profesor formador y el joven estudiante que se está formando ${ }^{33}$.

Como en otros países, la escuela finlandesa también tiene ciertas dificultades para reclutar a futuros profesores de matemáticas, física, química y lenguas extranjeras aunque no parece que los problemas sean tan grandes como en otros lugares. Ahora intentan atraer a la escuela a personas que quieren cambiar de profesión. La formación adicional que necesitan estas personas se hace a veces por internet. Aproximadamente a partir de 2000 aumentó la enseñanza a distancia y existe una formación docente a distancia para los estudiantes domiciliados en zonas aisladas y ya trabajan como suplentes; deben dedicar año y medio a lo que los otros hacen a tiempo completo en un año ${ }^{34}$.

\footnotetext{
${ }^{30}$ Jakku-Sihvonen y Niemi, 2007, pp. 58-62.

${ }^{31}$ Ibídem, pp. 216-219 y 226.

${ }^{32}$ Ibídem, p. 155.

${ }^{33}$ Ibídem, pp. 72, 84, 89, 90 у 98.

${ }^{34}$ Ibídem, p. 124.
} 


\section{Northern lights: una comparación entre países nórdicos}

Los países nórdicos son bastante similares en su política educativa y todos han sido influidos por los ideales de la nueva pedagogía. Por su suspicacia hacia las notas, los países han cambiado varias veces sus sistemas de notas, excepto Finlandia que sigue usando la misma escala de siempre. Los países retrasan la entrada a la educación del alumno como también retrasan el momento de dar notas hasta octavo grado, con la excepción de Finlandia. Suelen invertir bastante en la educación y hablar más de apertura que de exigencias, con la excepción de Finlandia.

A mediados de los años 90, Suecia adoptó nuevos currículos para el sistema escolar entero. El enfoque fue sobre las competencias generales que se debían promover y no sobre las materias. Los finlandeses introdujeron también un currículo nacional en 1994, un currículo un poco más libre, pero los resultados empezaron a ser diferentes entre las escuelas, y decidieron introducir otro marco curricular ya en 2004, un currículo con un claro enfoque en lo que debe saber el alumno en las diferentes materias. Se cree que Suecia sirvió como ejemplo negativo. En los resultados de PISA puede haber ayudado a Finlandia el hecho de que su estructuración de las materias sea bastante similar a lo que se mide ${ }^{35}$.

En cuanto a la preparación de los docentes, los finlandeses tienen ahora un nivel más alto que los demás países nórdicos. En particular, los docentes noruegos deben enseñar casi todas las materias hasta el décimo grado, y cuando se trata, por ejemplo, de las ciencias naturales, parece que su preparación no es suficiente.

En cuanto a la colaboración con los padres, Finlandia sale bien en comparación con los demás países escandinavos. Finlandia no publica los resultados escolares como los demás países nórdicos, pero aun así los padres tienen confianza en el sistema escolar. La confianza de los padres resulta un factor esencial para el buen resultado en Finlandia. Parece que cuando la escuela no funciona de manera óptima es cuando los padres intentan intervenir en el trabajo del colegio ${ }^{36}$.

Según las encuestas que acompañan las pruebas de PISA, hay mucho interés por la lectura entre los jóvenes en Finlandia mientras que el interés por la lectura está bajando en primer lugar en Noruega pero

35 Tomas Matti (ed.), Northern Lights on PISA 2006. Differences and Similarities in the Nordic Countries, 2009, pp. 35, 38-39 y 43.

${ }^{36}$ Ibídem, pp. 61 y 71. 
también en Suecia. Se constata algo importantísimo: el interés por la lectura corresponde más al éxito escolar que al nivel socioeconómico de los padres. El énfasis en la lectura podría ser lo esencial del "milagro" finlandés:

Estudiantes que tienen un nivel socioeconómico relativamente alto pero poco interés por la lectura obtienen resultados mucho peores que los estudiantes con un gran interés en la lectura combinado con un nivel socioeconómico relativamente bajo. ¡El interés en la lectura le gana al nivel socioeconómico! Esto es interesante, porque muchas veces el nivel socioeconómico suele ser un buen indicio de resultados de tests $^{37}$.

En particular es esencial que los alumnos lean también fuera del colegio y leen más las chicas que los chicos. Entre los alumnos a los que no les gusta leer y que evitan leer si pueden hay más chicos que chicas. En contraste, los chicos pasan más tiempo con los videojuegos. El informe dice claramente lo que saben todos los profesores, es decir, que una escuela que enfatiza la lectura puede cambiar la vida de los alumnos. Esta constatación va tan en contra de la nueva pedagogía que los pedagogos que colaboran en el informe no logran entender las consecuencias de lo que se dice; unas páginas más adelante en el informe se vuelve a hablar de la importancia de los niveles socioeconómicos. Tampoco mencionan la importancia de los factores como el esfuerzo, las exigencias o factores como la calidad de los profesores, del currículo y de los manuales ${ }^{38}$.

Comparando Finlandia con Suecia, Finlandia tiene una enseñanza más sistemática y Suecia una enseñanza más variada. Finlandia propone un buen programa pero igual para todos mientras que Suecia intenta individualizar la enseñanza. Finlandia atrae a muy buenos estudiantes a la carrera docente, lo cual ya no es el caso en Suecia. En Finlandia, los salarios de los docentes se mantienen en un nivel medio o medio alto, mientras que en Suecia los salarios han bajado lentamente en comparación con otras profesiones.

37 "Students with relatively high socio-economic backgrounds but weak interest in reading do much worse on tests than students with great interest in reading combined with relatively low socio-economic background. Interest in reading beats socio-economic background! This is interesting, not least because socio-economic background is usually a good predictor of test outcomes." P. 191.

${ }^{38}$ Ibídem, pp. 134-135 y 162. 
En resumen, los países escandinavos son muy similares y la nueva pedagogía ha tenido influencia en todos ellos pero, de la tradición común escandinava, Finlandia es el país que más ha mantenido un énfasis en las materias y en la especialización de sus profesores. El resultado es que los expertos consideran que los alumnos finlandeses están un año y medio más avanzados que los alumnos de los demás países nórdicos ${ }^{39}$.

\section{Comentarios extranjeros al "milagro" finlandés}

Un comentarista español ha ido a estudiar lo que sucede "en el bosque educativo finlandés" 40 . Insiste en que hay países distintos de Finlandia que también obtienen buenos resultados. Finlandia es un ejemplo de un buen modelo, pero no el único. Identifica como esencial que los alumnos finlandeses lean más que otros alumnos, que haya más competición que en otros países y que el resultado escolar no dependa del nivel socioeconómico de los padres. Cree importante la tradición histórica de respeto por la lectura, el énfasis que da el colegio a la lectura y la existencia de una extensa red de bibliotecas. El autor rechaza la idea de que sea la oscuridad y el frío lo que incentive a la gente a leer. Constata que los niños leen cosas de niños, los adolescentes leen periódicos y, como adultos, quizá leerán libros.

El comentarista español se ha fijado en particular en que se sirve gratuitamente una comida caliente a mediodía y que los profesores y los alumnos comen juntos. Cree que es un momento importante y que es cuando los profesores enseñan a los alumnos cómo comportarse en sociedad; la respetuosa conducta de los finlandeses en los lugares públicos podría haberse aprendido en la escuela.

Otro comentario viene de una experta española que ha visto lo mismo, pero lo interpreta de manera diferente, porque su plataforma es la nueva pedagogía ${ }^{41}$. Ha observado que la Comunidad de Madrid y Finlandia tienen una población de tamaño aproximadamente igual y de ahí el interés por hacer una comparación. Madrid invierte más dinero en educación, los salarios de los profesores son más altos y su forma-

${ }^{39}$ Ibídem, p. 190.

${ }^{40}$ Francisco Giménez Gracia, "El bosque educativo finlandés. Algunas claves del éxito de Finlandia en PISA", 2009.

${ }^{41}$ María José García Ruiz, Estudio Comparativo de la Educación: Finlandia y Comunidad de Madrid. Análisis y Recomendaciones, 2009. 
ción es por lo menos tan buena como en Finlandia. El número de días estudiados es, más o menos, el mismo. Una diferencia es que, después de terminar la secundaria obligatoria, sólo un $80 \%$ de los alumnos españoles opta por la formación teórica y sólo un $20 \%$ por la formación técnica, mientras que en Finlandia las cifras son un 50\% para cada tipo de formación. Sin embargo, piensa la autora, hay más "indicadores" positivos para Madrid que para Finlandia y le debería ir mejor a Madrid. Para ella, resulta una frustración que no sea así. En Madrid, un porcentaje menor de los alumnos termina la secundaria superior en comparación con la situación en Finlandia; también son menos los estudiantes que terminan una carrera universitaria completa. La autora cree que la explicación fundamental es que la población madrileña es más heterogénea, sin embargo, ya que los españoles aplican más la nueva pedagogía, les debería ir mejor, piensa la autora, y por eso el caso de Finlandia le resulta un enigma. Está tan convencida de que la nueva pedagogía es la correcta que no entiende lo que ve:

- Constata que la enseñanza finlandesa está más centrada en la explicación del profesor, por eso cree que los alumnos finlandeses son fundamentalmente pasivos ${ }^{42}$.

- Constata que la universidad tiene un numerus clausus, pero no comenta la conexión entre este dato y el esfuerzo de los alumnos.

- Constata que la formación propiamente pedagógica de los docentes sólo es de un año y que este año consiste en parte en prácticas, pero no subraya la diferencia con el nuevo magíster español obligatorio para los futuros docentes.

- Constata que Finlandia tiene una escuela comprensiva y obligatoria como España pero no habla de la flexibilidad del sistema finlandés.

- Critica que en Finlandia no se integre a todos los alumnos con necesidades especiales, pero no discute las consecuencias de tal integración ${ }^{43}$.

- Para la autora, no hay "milagro", porque cree que con una excelente formación docente, un estatus social elevado para los docentes, una fuerte identidad profesional, una cultura de "obediencia y autoridad", funciona cualquier modelo educativo. Para ella, la escuela refleja la sociedad y cree que Finlandia es una sociedad conservadora y autori-

\footnotetext{
42 Ibídem, p. 106.

${ }^{43}$ Ibídem, p. 132.
} 
taria, "oriental". Destaca tres características de la escuela finlandesa: su conservadurismo, su autoritarismo y su profesionalismo. Añade que el buen resultado depende de la homogeneidad de la población ${ }^{44}$. La conclusión general refleja las creencias pedagógico-religiosas de la autora. Para ella, Finlandia no es un ejemplo del triunfo de la escuela comprensiva y Finlandia no está en la vanguardia del desarrollo pedagógico, ni pretende estarlo.

Es muy importante tomar en serio las observaciones de esta autora, porque una gran parte de los pedagogos en los países desarrollados comparten esas mismas convicciones. Durante años han leído sobre la maldad de la escuela tradicional, denunciada como burguesa y elitista, y cuando se encuentran con un ejemplo de una escuela que es todo lo que quieren en cuestión de igualitarismo, no les gusta que se haya conseguido con los métodos contra los que ellos predican. El caso de Finlandia pone en tela de juicio lo que se presenta como la pedagogía moderna.

Una comparación entre los sistemas educativos en Francia y Japón arroja más luz sobre el tema que estamos estudiando ${ }^{45}$. El comentarista francés dice que Francia obtiene muy buenos resultados, pero sólo con la mejor mitad de los estudiantes; obtiene resultados mediocres con un $35 \%$; y obtiene resultados muy malos con un $15 \%$. El problema de Francia es qué hacer con el 15\% más bajo. En Japón se dice que hay más problemas ahora que en los años 90 , porque los diplomas ya no garantizan un buen empleo. Cada vez más se ve una polarización entre los alumnos que logran buenos resultados y los que se rebelan contra las exigencias. El comentarista cree que les va bien a las chicas por todas partes, porque las chicas suelen aceptar las reglas de las escuelas. A los chicos les gusta competir. El ideal sería que el alumno a la vez aceptara guiarse por las reglas y que le gustara competir. ¿Más o menos como los finlandeses?

Por si alguien cree que estamos hablando de algo genético y no de una manera cultural de organizar los estudios, es interesante el dato de que en Japón hay inmigrantes de Brasil que son hijos o nietos de japoneses. A estos jóvenes de aspecto japonés no les gusta estudiar y

${ }^{44}$ Ibídem, pp. 122-123, 133 y 143-145.

45 Jean-Francois Sabouret y Daisuke Sonoyama, Liberté, Inégalité, Individualité. La France et le Japon au Miroir de l'Éducation, 2008, pp. 50, 186, 195 y 305 . 
suelen dejar tan pronto como es posible los estudios ${ }^{46}$. Algo similar se puede decir de algunos de los finlandeses de habla finesa en Suecia que no logran los resultados que se logran en Finlandia ${ }^{47}$.

\section{Tradiciones, inteligencia, pragmatismo y flexibilidad}

Un ingeniero y profesor, funcionario de la Dirección General de las Escuelas Finlandesas en Helsinki, señala por qué Finlandia se libró de la politización de la educación que ha caracterizado a los demás países escandinavos: en Finlandia, hasta los años 90, había una situación política compleja con múltiples partidos y los políticos estaban ocupados formando gobiernos de coalición; ya que se cambiaba a menudo de gobierno, los gobiernos tenían que fiarse de los funcionarios ${ }^{48}$. En gran medida, los políticos dejaron trabajar a los funcionarios del Ministerio de Educación sin mucho intervencionismo.

También señala las tradiciones sociales en Finlandia como una explicación del éxito actual. Lo democrático se entiende en Suecia, cree, como discutir todo con todos constantemente, en Finlandia se entiende como votar a alguien y después dejar que la persona designada haga su trabajo; si no lo hace bien, se la saca y se nombra a otra. Tanto en la escuela como en la familia se acepta que decida alguien sin que los otros se sientan oprimidos por eso. La escuela es vista como un lugar de trabajo, los alumnos tienen derecho a divertirse y pasarlo bien, pero esta parte de su vida pertenece a la zona privada.

El entrevistado explica la actitud relativamente positiva ante las ciencias naturales a través del hecho de que la industria ha salvado a Finlandia en dos ocasiones relativamente recientes. La primera fue después de la segunda guerra mundial, cuando hubo que pagarle grandes sumas a la Unión Soviética, montándose una industria metalúrgica exitosa. La segunda fue durante la crisis al comienzo de los años 90, cuando se logró sacar adelante al país a través de las telecomunicaciones y

${ }^{46}$ Ibídem, p. 218.

47 Véase, entre otros estudios, Riita Eriksson, Biculturalism in Upper Secondary Education. The Long Term Effects of Finnish Language Programs on Students' Educational and Occupational Careers - A Swedish Case Study, 1994.

${ }^{48}$ Entrevista con Henrik Laurén, la Dirección General de las Escuelas Finlandesas, Helsinki, abril de 2010. 
la robótica. Los finlandeses saben que su supervivencia colectiva está atada a los esfuerzos y a los estudios.

Un factor importante para el éxito educativo es la exitosa propaganda a favor de la formación técnica. La mitad de los alumnos que salen de la comprensiva se dirige a la formación técnica. El éxito de esta variante tiene varias explicaciones: se han renovado las ofertas, las carreras muchas veces llevan a un puesto de trabajo y, finalmente, los salarios no son malos. Además, la formación técnica tiene una continuación en la educación superior si esto le interesa al alumno. Y también se ofrece la posibilidad de completar la formación técnica con cuatro materias teóricas para poder solicitar el ingreso en una carrera universitaria teórica.

Una persona encargada de la formación docente de los profesores suecoparlantes describe el proceso de selección que se utiliza en su región ${ }^{49}$. En su universidad, se reciben tres veces más solicitudes que el número de plazas disponibles. En el proceso de selección se miran las notas de los estudios de la secundaria superior, las notas de los exámenes escritos nacionales y el número de materias presentadas. Basada en esto, la universidad llama a una entrevista de selección. La entrevista corre a cargo de un profesor de pedagogía o de didáctica y de un profesor de la escuela de prácticas. Estos dos profesores observan el manejo del lenguaje del estudiante, su personalidad y su actitud de cara a su futura profesión. Casi nunca se acepta a alguien que no sea hablante nativo de sueco, es decir, que sea fineshablante. La formación finesa, por su parte, no suele aceptar a hablantes de sueco como lengua materna. La explicación es que se adjudica un valor muy grande a la lengua en la formación y los hablantes no nativos pocas veces dominan suficientemente bien la lengua como para ser buenos modelos lingüísticos. La lengua es el instrumento principal de los alumnos para aprender, subraya la profesora. El puntaje de la entrevista se junta al puntaje de los exámenes y de las notas del instituto. La formación que después se ofrece a los seleccionados es notablemente flexible porque los estudiantes pueden escoger una parte de las materias y pueden estudiar los cursos pedagógicos en el orden que les convenga.

Dentro de la formación docente se está intentando que, entre los profesores universitarios que enseñan a los futuros docentes, más profesores saquen el doctorado. El Estado finlandés subvenciona específi-

49 Entrevista con Cristina Nygren Landgärds, Åbo Akademi, Turku, abril de 2010. 
camente a las universidades para lograr esto y los municipios ofrecen empleos a profesores con un doctorado, tanto dentro de la secundaria superior como dentro de la escuela comprensiva. Las tesis escritas por estos profesores universitarios, igual que las tesis de magíster, escritas por los futuros profesores de colegio y de instituto, tratan generalmente de diferentes aspectos de la didáctica. Cuando se habla en Finlandia de la importancia de una formación docente basada en la investigación, hay que entender que esta investigación constituye una continuación de la actitud pragmática que caracteriza el sistema. Muchas veces las tesis se elaboran como una reflexión sobre una experiencia, insertada dentro del marco de otras experiencias descritas con anterioridad.

Los pocos alumnos que salen de la escuela comprensiva sin un certificado pueden completar su formación. Ya que son pocos, no suele haber suficientes alumnos como para formar un grupo entero, sino que esta enseñanza se organiza de manera diferente en cada caso. Finlandia no da subvenciones de desempleo a personas por debajo de los 25 años, sino que deben inscribirse en programas de prácticas o de formación técnica.

Como explicación de los éxitos educativos, una profesora responsable de una formación docente en finés señala elementos tan dispares como el respeto de la sociedad por la figura del profesor, el alto nivel de los candidatos a la docencia, la competición saludable entre algunas editoriales de manuales, la actitud generalizada de considerar que la escuela representa el trabajo de los alumnos y no otra cosa y, finalmente, la comida caliente que se sirve a mediodía y que hace que los alumnos tengan fuerzas para trabajar ${ }^{50}$. También hay problemas en la educación finlandesa. Uno es el número bajo de varones entre los docentes. Tantos hombres como mujeres solicitan plazas en la formación docente, pero los varones son eliminados porque tienen notas más bajas. Lo que salva a algunos varones son las entrevistas.

Unas mujeres responsables de la formación continua del profesorado suecoparlante y de la educación superior correspondiente a la formación profesional dan ejemplos de la flexibilidad y el pragmatismo finlandés ${ }^{51}$. Organizan cursos universitarios de verano, cursos por internet y cursos de formación docente que se pueden tomar en diferentes

${ }^{50}$ Entrevista con Riitta Asandi, Universidad de Turku, abril de 2010.

${ }^{51}$ Entrevista con Paula Lindroos y colaboradoras, Åbo Akademi, Turku, abril de 2010 . 
etapas de la carrera. Combinan la tecnología, las materias y los temas sociales. Sin embargo, no ven todo de color rosa en la escuela comprensiva finlandesa. Como profesionales y madres se preocupan por la integración de alumnos con problemas en el aula. Una de ellas cuenta que un experimento de integración hizo perder el contenido de un año entero al grupo en que estaba su hijo. También señalan la falta de atención a los jóvenes con talentos.

En la última etapa de la escuela obligatoria, con alumnos de entre 13 y 16 años, se ve que tampoco Finlandia está a salvo de los problemas de hoy ${ }^{52}$. Hay cierto absentismo y hay alguno que otro alumno que tiene que repetir el curso. Los profesores mandan un mensaje electrónico a los padres por lo menos una vez por semana para decir que todo está bien o para contar que hay algún problema.

El horario termina alrededor de las 14 horas y sólo el jueves se continúa hasta las $15 \mathrm{~h} 30$. Los alumnos reciben los manuales que necesitan como préstamo. Se hacen excursiones con los alumnos del último año para que conozcan diferentes escuelas de formación técnica. Los alumnos mayores funcionan también como personas de contacto para los alumnos más jóvenes. Los alumnos dicen dedicar una hora cada tarde a los deberes o quizá dos si hay prueba. Tienen una prueba escrita cada semana según un esquema que se establece al comienzo del año escolar.

En cierto grupo de quinceañeros, tres alumnos son atletas de alto nivel; están ausentes frecuentemente, pero son ambiciosos y recuperan lo perdido con la ayuda de un compañero. En un grupo hay un chico con el síndrome de Asperger que no dice nada en el aula, pero saca muy bien los exámenes de matemáticas. Oficialmente no hay itinerarios en la escuela comprensiva finlandesa, pero se puede observar que dentro de una misma aula hay alumnos que trabajan con un profesor de educación especial, otros que trabajan en el nivel "normal" del curso y otros que trabajan en un nivel más alto para sacar notas más elevadas. Como en cualquier país, cuando hay muchas actividades simultáneas en un aula, se produce un susurro que puede molestar cuando un alumno intenta concentrarse. También en Finlandia algunos alumnos, a los que les queda mes y medio para terminar la escuela obligatoria, miran por la ventana con una expresión que revela que sus pensamientos están lejos del aula.

52 Entrevista con Christer Karlsson, director de Sankt Olafsskolan, Turku, abril de 2010 . 
El director de un instituto prestigioso de secundaria superior menciona que su instituto sólo acepta a alumnos con 7 de promedio, es decir, son estudiantes buenos ${ }^{53}$. Hay más del doble de solicitudes en comparación con las plazas. En Helsinki hay institutos especializados en deporte y en arte que tienen un "corte" muy alto. Por ahora, no existen institutos especializados en materias teóricas. Como contraste, en las ciudades pequeñas se pueden dar institutos que admitan a todos los alumnos que soliciten una plaza y donde el ritmo de trabajo sea relativamente relajado. Los alumnos finlandeses no eligen una línea o un programa, sino que deben juntar 75 cursillos para graduarse. Algunos de estos cursos son obligatorios pero los otros se pueden combinar según el interés del alumno. Es decir, el sistema es extraordinariamente flexible. Hacia el final de los tres años, los alumnos se presentan a cuatro exámenes escritos nacionales, pero pueden presentarse ya en el otoño y volver a hacer por lo menos la prueba en la primavera, si no les sale tan bien como quisieran. Los alumnos ambiciosos quizá se presenten para rendir siete $u$ ocho materias. Pueden presentarse a un examen sin ir a las clases correspondientes. También pueden estudiar una carrera de formación técnica y completarla con cuatro asignaturas teóricas y así sacar dos exámenes.

El horario también merece atención. Muchas veces se trabaja en períodos bastante largos, pero con las materias "pesadas" por la mañana y las optativas, las estéticas y el deporte por la tarde. Además, esa "tarde" es muy breve, porque suele terminar a las 14 horas. Sólo el jueves el horario suele terminar a las $15 \mathrm{~h} 30$, lo cual les parece a todos un día muy largo. Después de terminada la escuela, los alumnos típicamente participan en las actividades de diferentes clubes o hacen deporte.

El horario escolar está organizado en períodos de seis o siete semanas después de las cuales los alumnos terminan los cursillos en cuestión y empiezan con otros. Hay clases para las que hay que estudiar fuertemente de manera tradicional pero se puede observar también una tendencia a enseñar a través de tareas prácticas que deben realizar los alumnos. Por ejemplo, los alumnos deben buscar un artículo periodístico sobre cierto tema, resumirlo en clase y comentarlo. En otra clase, deben preparar un discurso de tres minutos pensando en los tres elementos

${ }^{53}$ Entrevista con Bertel Wahlström, director de Katedralskolan, Turku, abril de 2010 . 
de la retórica clásica: el logos, el ethos y el pathos. En una clase de lengua extranjera deben discutir de dos en dos diferentes profesiones, preguntar al compañero qué profesión le gustaría tener y por qué. En algunas materias, los grupos son grandes, pero también pueden consistir de 12 a 15 alumnos. También en la secundaria superior los alumnos reciben una comida caliente gratuita a mediodía, pero tienen que comprarse los manuales.

En un pasillo aparece Víctor de Iquique. Está un año en Turku como alumno de intercambio. Está encantado con todo. Habla del buen ambiente y del respeto mutuo entre alumnos y profesores, de la comida caliente gratuita a mediodía, de que los alumnos se comportan de manera correcta en el comedor, de que se permite llevar el pelo bastante largo en el instituto, de que hay chicas también y no "puro hombre" como en su instituto, de que su horario le permite dormir dos horas extras una mañana cada semana.

\section{¿Cómo podría Chile inspirarse en Finlandia?}

El éxito del sistema educativo finlandés no se basa en cierta ideología educativa, sino en una serie de decisiones que juntas crean un buen ambiente para el estudio. Al hablar de la educación finlandesa hay que mencionar la flexibilidad con la que se combinan el nivel nacional y el local. Los finlandeses siguen modificando su sistema para mejorarlo aún más. Por ejemplo, recientemente se ha introducido una importante reforma universitaria y se está reformando el marco curricular de la escuela comprensiva. Ya que muchas decisiones se toman a nivel local, no hay un solo modelo finlandés. Sin embargo, hay algunos rasgos que se podrían señalar. Los profesores son inteligentes, bien preparados, flexibles, respetuosos y respetados. Se dirigen a los alumnos con la oferta de abrirles el mundo a través del desarrollo personal. Solicitan respuestas, ofrecen comentarios, seguros de sí mismos y de su tarea como docentes. Es notable que muchos de los deberes asignados tengan la forma de una pequeña investigación o de la preparación de una intervención oral en el aula. Es difícil ver que una educación privada pudiera dar más de lo que da la comprensiva finlandesa. Se podría hablar de un proceso de cualificación del joven.

De todo esto, ¿qué parte podría servir de inspiración para las reformas chilenas? Como se ha indicado, se trata de algo muy complejo, 
pero las ideas clave podrían ser la calidad de los profesores y la flexibilidad. Se podrían seleccionar algunas ideas:

- En la primaria y en la secundaria inferior es útil trabajar con currículos concretos y hacerlos cumplir. Es útil introducir reglas que impidan que los alumnos pasen al grado superior sin conocer lo que corresponde al grado que ha terminado.

- En la formación docente es importante atraer a estudiantes inteligentes que ya tengan una buena cultura general. Esto es tan importante para la primaria como para la secundaria. Quizá se podría crear una formación docente con un numerus clausus y pagar un salario a los estudiantes en cuestión durante su formación con la condición de que enseñen, por ejemplo, por lo menos durante tres años.

- En cuanto a los profesores en ejercicio, se podrían crear programas que fortalezcan su lenguaje y sus capacidades lectora y reflexiva. Lo ideal sería poder ofrecer un aumento salarial a los que se vayan formando más.

- Leer, leer y leer y eso en todos los niveles.

\section{BIBLIOGRAFÍA}

Barber, Michael y Mona Mourshed. How the World's Best-performing School Systems Come Out on Top. McKinsey, 2007. www.mckinsey.com/ locations/ukireland/index.aspx.

Enkvist, Inger. La Educación en Peligro. Madrid: Eunsa [2000], 2010. - Repensar la Educación. Madrid: Eunsa [2006] 2010.

Eriksson, Riita. Biculturalism in Upper Secondary Education. The Long Term Effects of Finnish Language Programs on Students' Educational and Occupational Careers - A Swedish Case Study. Estocolmo: Universidad de Estocolmo, 1994.

Fölster, Stefan et al. Den orättvisa skolan. Estocolmo: Hjalmarsson \& Högberg, 2009.

García Ruiz, María José. Estudio Comparativo de la Educación: Finlandia y Comunidad de Madrid. Análisis y Recomendaciones. Madrid: Comunidad de Madrid, 2009.

Giménez Gracia, Francisco. "El Bosque Educativo Finlandés. Algunas Claves del éxito de Finlandia en PISA". En Cuadernos del Pensamiento Político, 23, julio-septiembre, 2009.

Häikio, Martti. Nokia - vägen till framgång. Londres: Prentice Hall, 2003.

Hautamäki, Jarkko et al. PISA 06. Analyses, Reflections, Explanations. Helsinki: Ministerio de Educación, 2008: 4.

Jakku-Sihvonen, Ritva y Hannele Niemi (eds). Education as a Societal Contributor. Frankfurt am Main: Peter Lang, 2007. 
Research-based Teacher Education in Finland. Reflexions by Finnish Teacher Educators. Turku: Finnish Educational Research Association, 2006.

Kuikka, Martti T. A History of Finnish Education. Helsinki: Otava, 1992.

Matti, Tomas (ed). Northern Lights on PISA 2006. Differences and Similarities in the Nordic Countries. Copenhague: Nordic Council of Ministers, 2009.

Ministerio de Educación de Finlandia. National Core Corriculum for Basic Education, 2004. Helsinski, 2004.

OCDE. PISA 2003. Svenska femtonåringars kunskaper och attityder $i$ ett internationellt perspektiv. Estocolmo: Skolverket, rapport 254, 2004. Informe PISA 2006. Competencias Cientificas para el Mundo del Mañana. OCDE, Santillana, Ministerio de Educación.

- PISA 2006. The Programme for International Student Assessment. París: OCDE, 2006.

- PISA 2006. 15-åringars förmåga att förstå, tolka och reflektera naturvetenskap, matematik och läsförståelse. Estocolmo: Skolverket, rapport 207, 1007.

Pont, Beatriz, Deborah Nusche y David Hopkins (eds). Improving School Leadership. Vol. 2. Case Studies on System Leadership. OCDE, 2008.

Pont, Beatriz, Deborah Nusche y Hunter Moorman (eds). Improving School Leadership. Vol. 1. Policy and Practice. OCDE, 2008.

Robert, Paul. La Finlande: Un Modèle por la France? Les Secrets de la Réussite. Issy-les-Moulineux: ESF éditeurs, 2008.

Sabouret, Jean-Francois y Daisuke Sonoyama. Liberté, Inégalité, Individualité. La France et le Japon au Miroir de l'Éducation. París: CNRS, 2008.

Sourander, Åsa. Sisu i klassurmmet. Fem framgångsfaktorer från Finland som ger resultat. Malmö: Epago, 2009. 